1977-08-01

\title{
The synthesis of novel macrocyclic multidentate compounds from dioxodioic acids (1)
}

\author{
R. Elliott Asay \\ Brigham Young University - Provo
}

Follow this and additional works at: https://scholarsarchive.byu.edu/etd

\section{BYU ScholarsArchive Citation}

Asay, R. Elliott, "The synthesis of novel macrocyclic multidentate compounds from dioxodioic acids (1)" (1977). Theses and Dissertations. 8158.

https://scholarsarchive.byu.edu/etd/8158

This Thesis is brought to you for free and open access by BYU ScholarsArchive. It has been accepted for inclusion in Theses and Dissertations by an authorized administrator of BYU ScholarsArchive. For more information, please contact ellen_amatangelo@byu.edu. 
THE SYNTHESIS OF NOVEL MACROCYCLIC MULTIDENTATE

COMPOUNDS FROM DIOXODIOIC ACIDS (1)

1977

A Manuscript of a Journal Article

Presented to the

Department of Chemistry

Brigham Young University

In Partial Fulfillment

of the Requirements for the Degree

Master of Science

by

R. Elliott Asay

August 1977 
This article by R. Elliott Asay is accepted in its present form by the Department of Chemistry at Brigham Young University as satisfying the thesis requirement for the degree of Master of Science. 
TABIE OF CONTENTS

Page

List of Figures ... . . . . . . . . . . . . . . . iv Abstract of the Article ...................... 1 Article ............................. 2 Experimental. ...................... 13 Acknowledgements. . . . . . . . . . . . . . . . 22 References and Notes. . . . . . . . . . . . . . 23 Appendix. . . . . . . . . . . . . . . . . . . 25

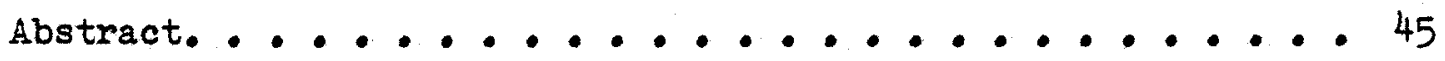




\section{LIST OF FICURES}

Page

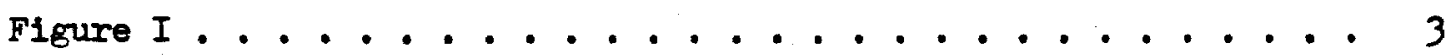

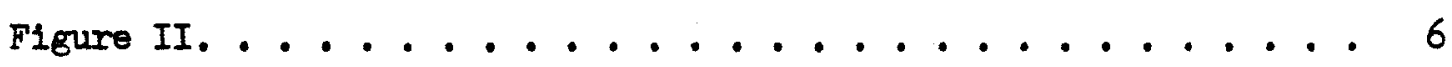

Figure III .................... 8

Figure IV. ................... . Il 


\section{ABSTRACT}

A series of novel macrocyclic multidentate crown compounds have been prepared from a series of dioxodiolc acids. The dioxodiolc acids were prepared by treating various oligoethylene glycols or amines with maleic, succinic, citraconic, and glutaric anhydrides. The crown compounds were then synthesized from the dioxodioic acid chlorides obtained from the diacids and various oligoethylene glycols or ethylene dlamine. The following macrocyclic compounds have been prepared: $1,4,9,12$-tetraoxacyclohexadecane-5,8,13,16-tetrone $(1) ; 1,4,7,10,15,18$ hexaoxacyclodocosane-11, 14,19,22-tetrone $(2) ; 1,4,-$ dioxa-9,12-diazacyclohexadecane-5,8,13,16-tetrone (3); 1,4,7-trloxa-12,15-diazacyclonoadecane-8,11, 16,19-tetrone $(\underset{2}{4}) ; 1,4,7,10$-tetraoxa-15,18-diazacyclodocosane-11, 14,19,22-tetrone $(\underset{2}{5}) ; 4$-benzyl-1,7,12,15-tetraoxa-4azacyclononadecane-8,11,16,19-tetrone $(6)$ : $1,4,7,12,15,18$-hexaoxacyclodocosa-9,20-diene-8,11,19,22-tetrone (?); and 9,21-dimethyl$1,4,7,12,15,18$-hexaoxacyclodocosa-9, 20-diene-8,11,19,22-tetrone ( (Figure I). 
The cation complexing properties of cyclic polyethers have been studied extensively, ${ }^{3-6}$ and have been found, in certain instances, to resemble those of the cyclic antibiotics valinomycin and nonactin.? The availability of synthetic cyclic polyethers and related compounds makes possible a systematic study of the factors which determine complex stability and which affect cation selectivity by macrocyclic compounds. One objective of our research program is to prepare and study a series of multidentate compounds which resemble naturally occurring macrocyclic compounds.

This work reports the synthesis of the following compounds containing multiple ester and amide moieties in addition to ether groups $^{3-6}$ (see Figure I). These compounds include 1,4,9,12-tetraoxacyclohexadecane-5,8,13,16-tetrone $(I) ; 1,4,7,10,15,18$-hexaoxacyclodocosane-11,14,19,22-tetrone $(2) ; 1,4$-dioxa-9,12-diazacyclohexadecane5,8,13,16-tetrone (3); 1,4,7-tr10xa-12,15-diazacyclononadecane$8,11,16,19$-tetrone $(\underset{\sim}{4}) ; 1,4,7,10$-tetraoxa-15,18-diazacyclodocosane$11,14,19,22$-tetrone (5); 4-benzy1-1,7,12,15-tetroxa-4-azacyclononadecane-8,11,16,19-tetrone $(6) ; 1,4,7,12,15,18$-hexaoxacyclodocosa9,20-diene-8,11,19,22-tetrone (?); and 9,21-dimethyl-1,4,7,12,15,18hexaoxacyclodocosa-9,20-diene-8,11,19,22-tetrone (8) (Figure I). Also included is a report of the synthesis of a serles of dioxodioic acids needed for the production of these macrocyclic compounds.

The synthesis of macrocyclic esters has been reported previously. Dewes and coworkers ${ }^{8-10}$ have prepared several similar compounds which contain a number of di- and tetra-esters from phthalic and maleic acid systems. They prepared cyclic ester compounds from the reaction of dipotassium salts of phthalic or maleic acid with a serles 
Figure I

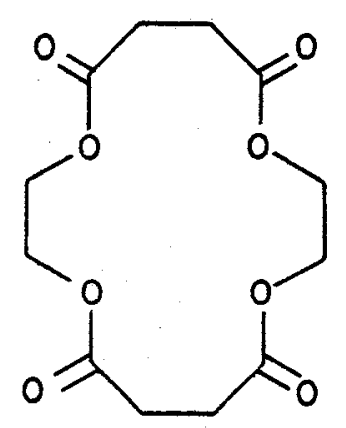

$\frac{1}{2}$

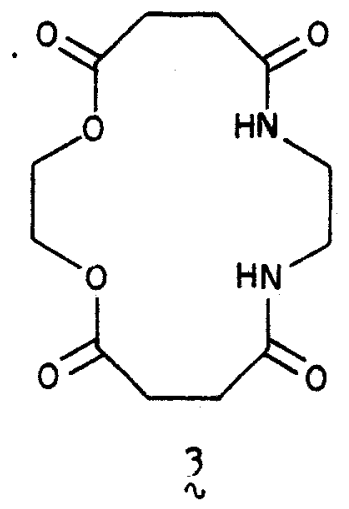

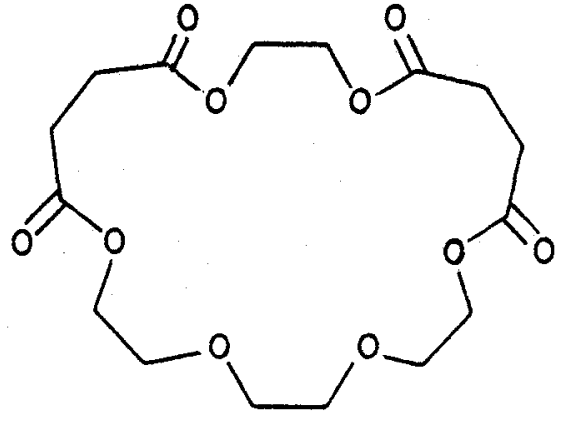

2

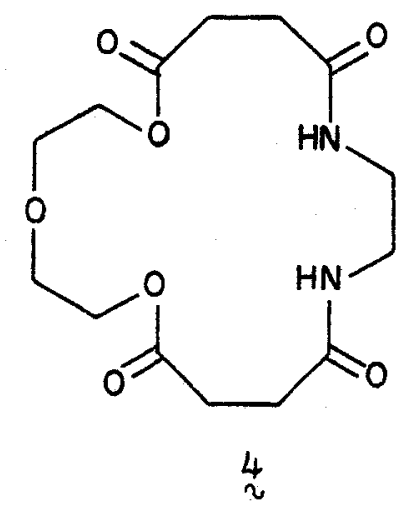



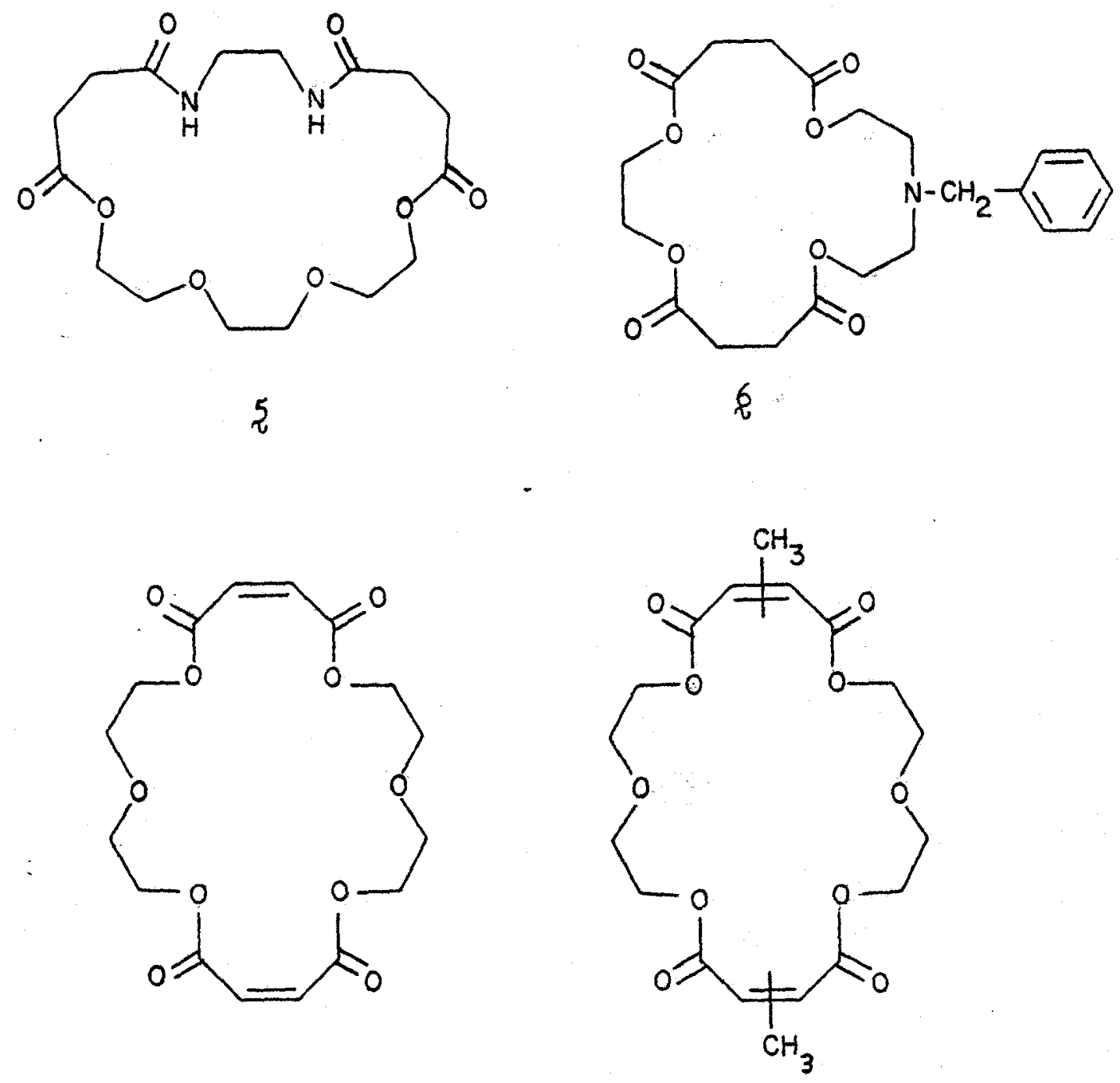

2

8 
of alkyl and alkynyl dibromides to make 10-34 membered ring compounds. Their compounds, however, did not contain the ethylene oxide molety. We recently reported the synthesis of crown ether-esters which have one diacid molety, 11,12 but the synthesis of crown ether-esters containing two diacid moleties has not been reported.

\section{Preparation of Starting Materials}

The dioxodioic acids needed for this study were prepared by treating various oligoethylene glycols with succinic, maleic, and citraconic anhydrides. The following compounds have been prepared: ethylene bis(hydrogen succinate) (q); oxydlethylene bis(hydrogen succinate) (10); ethylenebis(oxyethylene) bis(hydrogen succinate) ( $\left.\frac{17}{n}\right)$; oxydiethylene bis(hydrogen maleate) $\left(\frac{12}{n}\right)$; and oxydiethylene bis(hydrogen citraconate) (13). Related diolc acids prepared from various diamines and glycols and succinic or glutaric anhydride are also reported in this paper. These include: $N, N^{\prime}$-ethylenedisuccinamic acid $(14) ; \underline{N}, \underline{N}^{\prime}$-ethylene-bis (N-methylsuccinamic acid) (15); $\gamma, \gamma^{\prime}$-dioxo-1,4-piperazinedibutyric acid $(16) ; 2-(3-c a r b o x y-\underline{N}-$ methylproplonamido) ethyl hydrogen succinate (17); thiodiethylene bis(hydrogen succinate) ( 18 ); and oxybls(ethyleneoxyethylene) bis(hydrogen glutarate) (19) (Figure II).

Results and Discussions

The formation of compounds 2 and 10 has been reported previously from the glycols and succinic acid; however, no physical constants were given. 13 Esterification of glycols with various acids such as terephthalic, fumaric and succinic has also been presented. 
Figure II

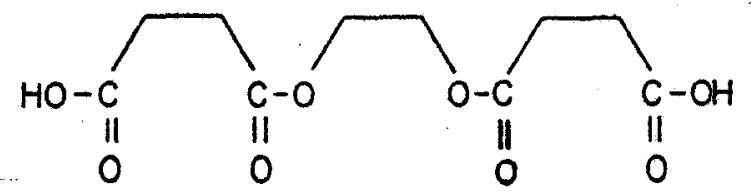

2
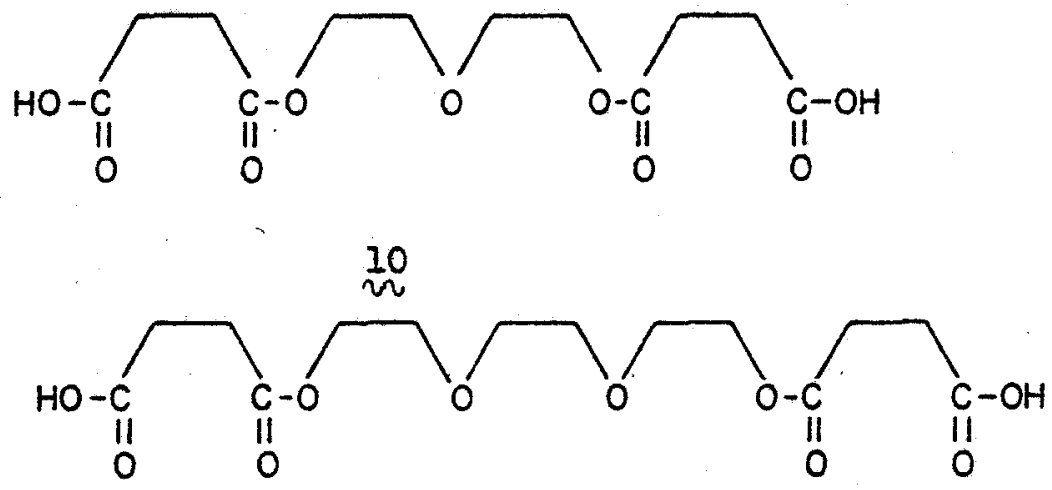

II
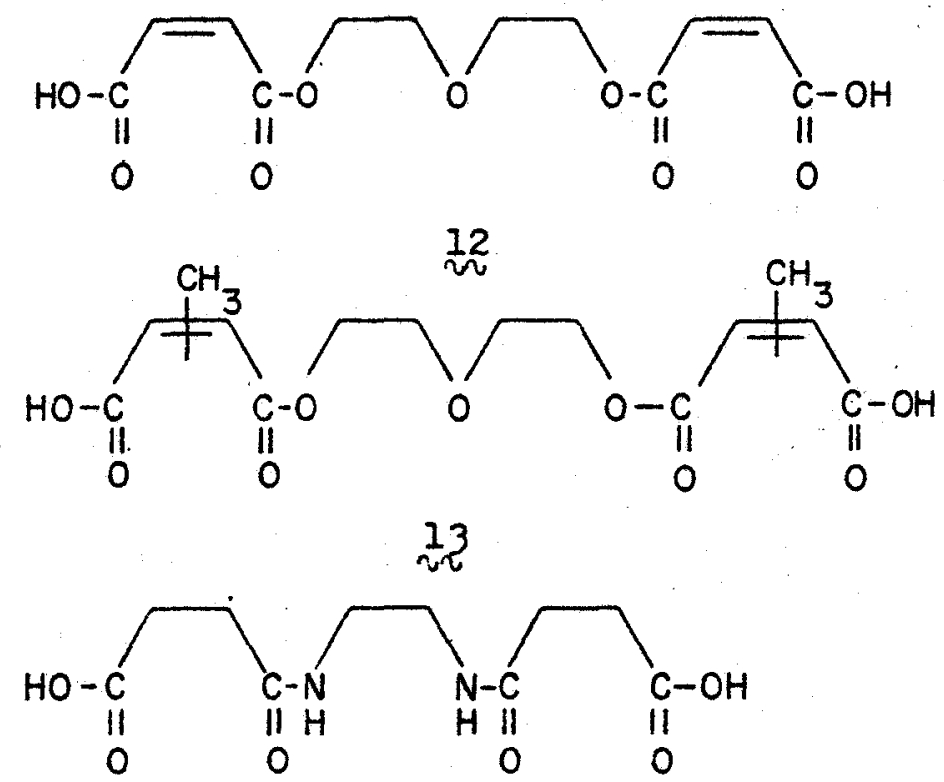

14 

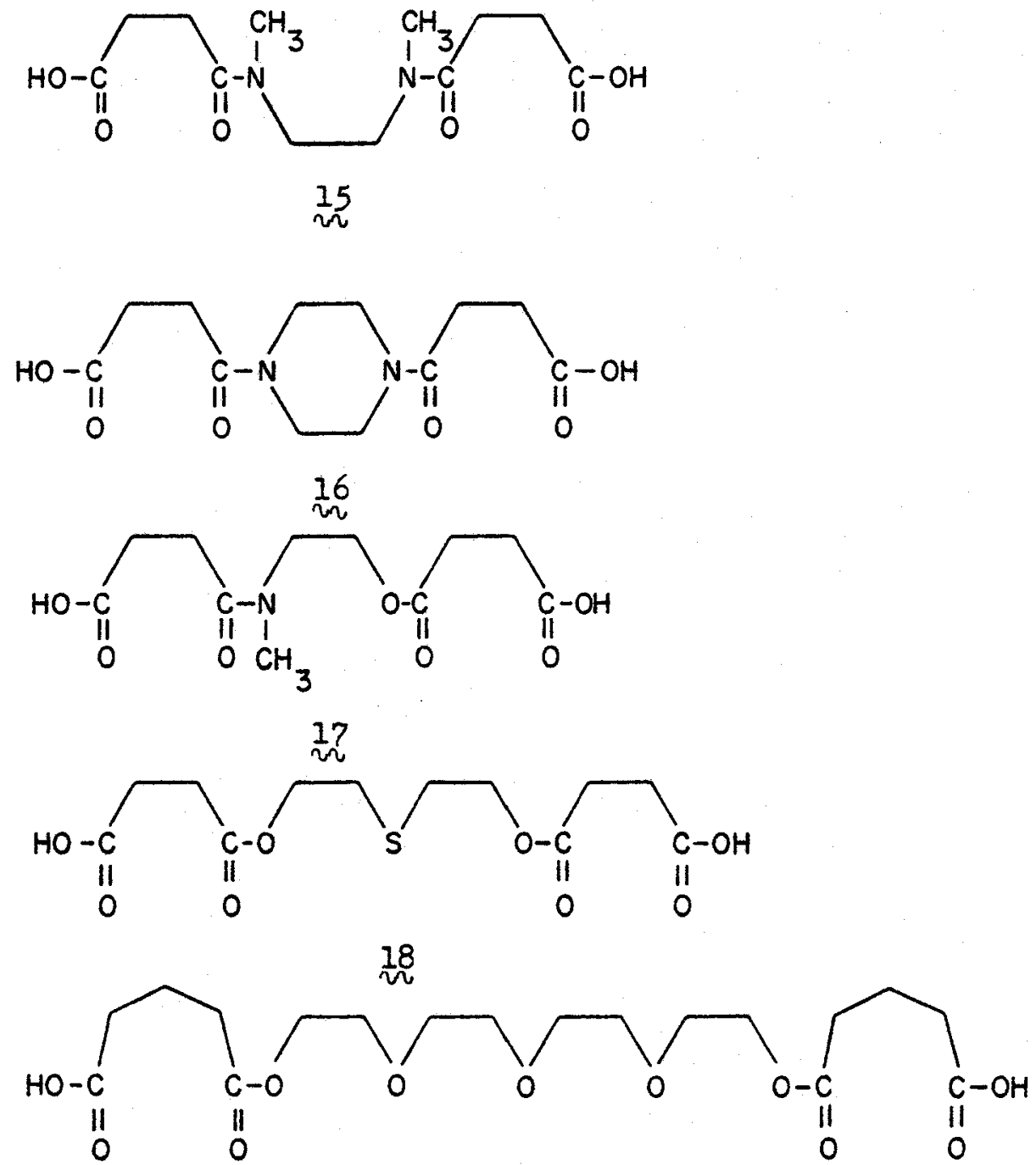

12 
Figure III
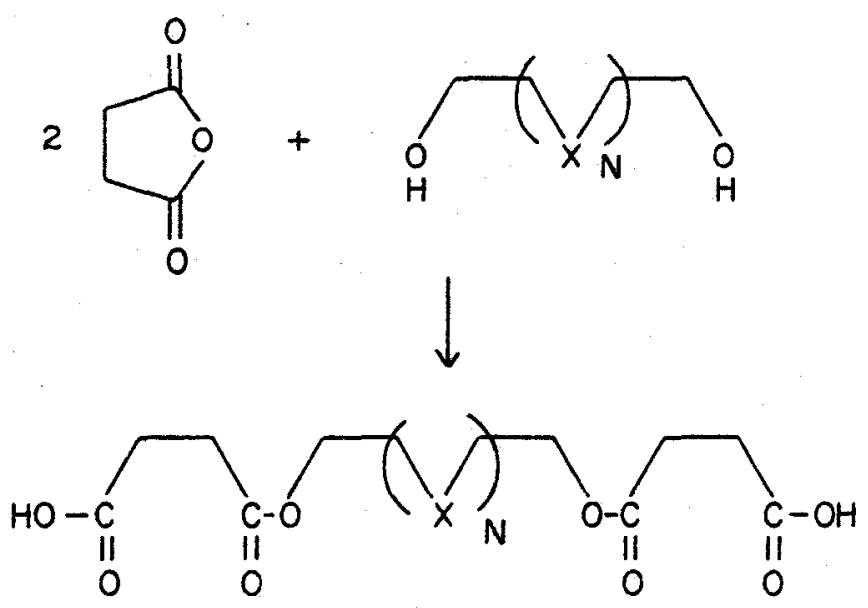

$$
\begin{array}{ll}
N=0,1,2 & N=1 \\
X=0 & X=S
\end{array}
$$<smiles>[X]CCN</smiles>

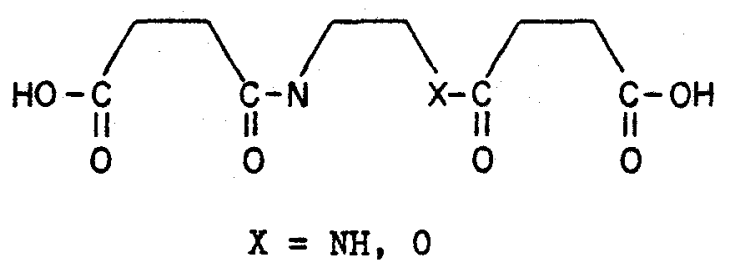


These products contained one acid group. ${ }^{14}$ Dioic acids containing amide functions have not been reported although 2,6-piperazine dicarboxylic acids are known. 15 Compounds somewhat similar to these have also been reported by other workers. ${ }^{16,17}$

The structures proposed for the dioxodioic acid compounds are consistent with those determined from the nmr and ir spectra, elemental analysis of the products or a macrocyclic derivative, and molecular weight determinations. The diacids containing the ester moieties all exhibited an ir band at 1730-1740 cm -1 and a band at 1690-1720 $\mathrm{cm}^{-1}$ indicative of the ester and carboxylic acid carbonyl groups, respectively. Those compounds possessing the amide function $\left(\sqrt[1]{\sim}-1 \eta\right.$ ) all contained bands at $1620-1600$ and $1550-1500 \mathrm{~cm}^{-1}$ indicative of the amide group as well as the ester carbonyl band at $1710-1740 \mathrm{~cm}^{-1}$.

The nmr spectra of the compounds are most revealing. The ethylene hydrogens for the succinic acid portions for all acids derived from succinic anhydride $\left(9, \frac{11}{n}, 14,15,16,17\right.$, and 18 ) exhibited $\mathrm{nmr}$ peaks at $2.68 \pm 0.02 \delta$ with the exception of compound 10 which exhibited a peak at $2.55 \delta$. The glutarate propylene hydrogens of compound 19 exhibited a triplet peak at $2.48 \delta$ and a multiplet at $2.03 \delta$. The unsaturated compounds 12 and 13 exhibited the usual vinyl hydrogen peaks in the $\mathrm{nmr}$ spectra. All ester methylene hydrogens appeared at $4.35 \pm 0.10 \delta$ while the ether methylene hydrogens appeared at $3.70 \pm 0.10 \delta$ in the $\mathrm{nmr}$ spectra. The hydrogens on the carbon next to sulfur on compound 18 exhibited a peak at $2.86 \delta$. The amide diacids $\left(\frac{1}{2}-17\right)$ exhibited the expected nmr peaks. For compound 16 , the amide methylene peaks occurred as a triplet at 
$3.68 \delta$ with small triplet peaks appearing at $3.40 \delta$ and $3.88 \delta$ as well, whose total peak area (3.40-3.88 $\delta$ ) equals eight hydrogens. SpraEg, in an nmr study of $\mathrm{N}, \mathrm{i}$-disubstituted piperazine derivatives, found cis-, trans- isomers with the trans- form constituting the major product. ${ }^{18}$ Unusual splitting of the methyl peaks from compounds 15 and 17 was also observed in the $\mathrm{nmr}$ at 3.04 and $3.06 \mathrm{\delta}$, respectively. Miron and co-workers also noted such splitting of MMe groups in amide moleties of polymers which they attributed to hindered rotation about the amide bond. ${ }^{19}$

Compounds $2-\frac{1}{2} 3$ can be easily transformed into the corresponding diacid chlorides by the action of thionyl chloride. The acid chlorides were then used to form the macrocyclic compounds. Diacid chlorides for compounds $\frac{14-18}{2}$ cannot be formed by the action of thionyl chloride due to the destruction of the amide function within the diacid. 20 For example, when compound 14 was treated with thionyl chloride, a cyano bond was observed in an ir spectrum of the reaction mixture. Metal complexation studies of these diacids are presently being undertaken and will be reported in a future paper.

The novel macrocyclic compounds shown in Figure I were prepared by treating the appropriate glycol or ethylene diamine with diacid chlorides prepared from the appropriate dioxodioic acid, Figure IV.

The structures proposed for these compounds are consistent with those determined from the ir and nmr spectra, molecular weight determinations, and elemental analyses. These macrocyclic compounds exhibited ir peaks comparable in some respects to the diacids from which they were derived. The ester moleties all exhibited an ir band 
Figure IV
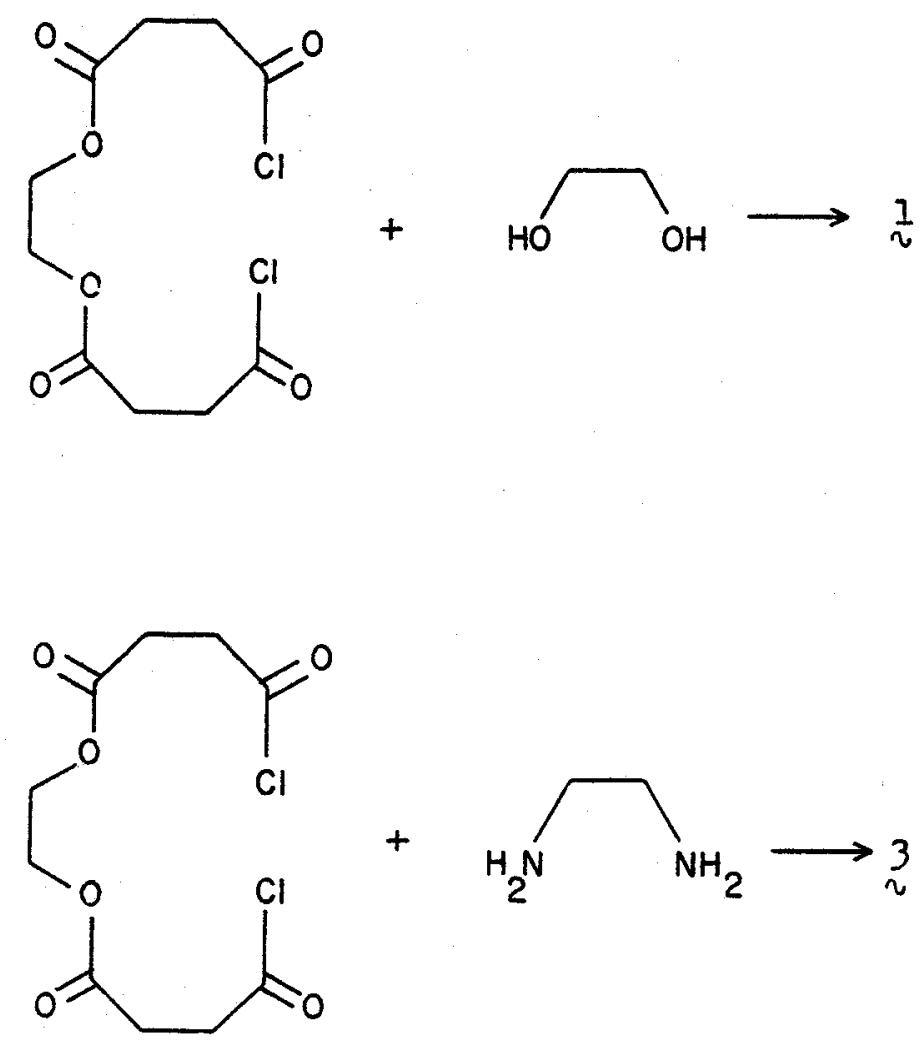
at 1720-1740 $\mathrm{cm}^{-1}$ and the amide moieties all exhibited bands at $1660-1640 \mathrm{~cm}^{-1}$ and $1560-1550 \mathrm{~cm}^{-1}$.

The nmr spectra also are comparable to the diacids. The ethylene hydrogens for the succinic acid moleties of compounds $\left(\frac{7}{2}-6\right)$ exhibited nmr peaks at $2.65 \pm 0.02 \delta$. All ester methylene hydrogens appeared at $4.30 \pm 0.10 \delta$ while the ether methylene hydrogens appeared at $3.50 \pm 0.10 \delta$. Methylene hydrogens next to nitrogen exhibited nmr peaks at $3.33 \pm 0.10 \delta$. The vinyl hydrogens of compounds $Z$ and $\underset{\sim}{8}$ exhibited peaks at $6.90 \pm 0.10 \delta$. Yields for these crown compounds ranged from 1 to $68 \%$. The low yields were a result of the difficulty in purification of the diacid chlorides before reaction with the appropriate glycol. Several of the compounds which were solids exhibited water peaks in ir spectra; however, after vacuum diying, these peaks were greatly reduced or removed entirely. Work is now in progress to determine the complexation properties of these compounds. 


\section{EXPERTMENTAL}

All ir spectra were obtained on a Hilger and Watts H-1200 Infragraph. The nmr spectra were obtained on a Varian EM-390 spectrometer. The elemental analysis were performed by Galbraith Laboratorles, Knoxville, Tennessee. The molecular welght determinations for the diacids were performed either by a base titration or on a Hitachi Perikin-Elmer 115 Molecular Welght apparatus. Melting points are uncorrected.

Starting Materials

Most of the starting glycols, amines and anhydrides were used as purchased: ethylene glycol (Mallinckrodt), diethylene glycol (Eastman), triethylene glycol (Baker), 2,2'-(benzylimino) diethanol (Pfaltz and Bauer), ethylenediamine (MCB), piperazine (Aldrich), sym-dimethylethylenediamine (Aldrich), 2-(methylamino)ethanol (Aldrich), thiodiethylene glycol (Fluka), succinic anhydride (Eastman), citraconic anhydride (Aldrich), maleic anhydride (MCB), glutaric anhydride (Aldrich), succinyl chloride (Aldrich).

\section{General Synthesis}

The diacids were prepared by slowly adding the glycol or diamine to the anhydride in $500 \mathrm{ml}$ of benzene at $50^{\circ} \mathrm{C}$. The resulting mixture was stirred for at least three days. After the reaction was stopped, the upper benzene layer was renoved and the 
lower product layer was purified by recrystallization or by extraction techniques. In the case of most amide compounds, the product solidified in the benzene. After benzene removal, the crude product was recrystallized. Specific details are given for each of the diacid compounds.

The diacid chlorides from compounds $2-13$ were prepared by slowly adding 0.4 mole of thionyl chloride to the diacid ( 0.1 mole) in 1 liter of benzene and $2 \mathrm{ml}$ of pyridine. The resulting mixture was stirred at room temperature for 2 hours. After the reaction was stopped, the mixture was filtered and the benzene was removed under vacuum. The resulting liquid product was not further isolated or characterized but was used directly in the synthesis of the macrocyclic crown compounds.

All macrocyclic crown compounds except compound $I$ were prepared by treating the diacid chlorides from compounds $2-13$ with the appropriate glycol or ethylenediamine. The glycol and diacid chlorlde each dissolved in $200 \mathrm{ml}$ of benzene or THF were slowly added simultaneously to $600 \mathrm{ml}$ of stimred benzene at $50^{\circ} \mathrm{C}$. Excess ethylene diamine was added where appropriate to complex the hydrochloric acid generated during the reaction to avoid complexation in the amide containing crown compounds. The resulting mixture was stirred at $50-60^{\circ} \mathrm{C}$ for at least two days. After the reaction was stopped, benzene was removed under vacuum. The crude product was then purified by recrystallization or by alumina chromatography using hexane with increasing amounts of chloroform as the eluant. Specific detalls are given for each crown compound. 
Diacids

Ethylene bis(Hydrogensuccinate) (?).

Ethylene glycol ( $31 \mathrm{~g} ., 0.50 \mathrm{~mole})$ and succinic anhydride (100 g., 1.00 mole) were used. The product (127.71 g., 97.5\%) was recrystallized from an ethyl acetate-hexane mixture, m.p. dec. $>80^{\circ}$; Ir: $1740,1705,1170 \mathrm{~cm}^{-1}$; nmr: (8) 2.68 (s, 8H $\left.\mathrm{OCCH}_{2} \mathrm{CH}_{2} \mathrm{COOH}\right), 4.34\left(\mathrm{~s}, 4 \mathrm{H}, \mathrm{COOCH}_{2}\right), 9.93(\mathrm{~s}, 2 \mathrm{H}, \mathrm{COOH})$. Molecular weight: Calcd: 262.2. Found: 262.7. A satisfactory elemental analysis was obtained via its derivatives, compounds $1, \eta^{3}$ and 6 . Oxydiethylene bis(Hydrogensuccinate) $(10)$.

Diethylene glycol (53 g., $0.50 \mathrm{~mole})$ and succintc anhydride (100 g., 1.00 mole) were used. The product (127 g., 84\%) was recrystallized from an ethyl acetate-hexane mixture; m.p. 70-72 ;

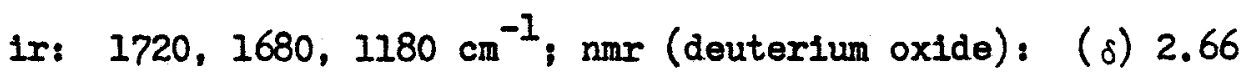
$\left(\mathrm{s}, 8 \mathrm{H}, \mathrm{OCCH}_{2} \mathrm{CH}_{2} \mathrm{COOH}\right), 3.64\left(t, 4 \mathrm{H}, \mathrm{OCH}_{2}\right), 4.18\left(t, 4 \mathrm{H}, \mathrm{OOCCH}_{2}\right)$. Molecular weight: Calcd: 306.3. Found, 276. A satisfactory elemental analysis was obtained via its derivative, compound 4 . Ethylenebis(oxyethylene) bis(Hydrogensuccinate) $\left(\mathrm{II}_{\mathrm{N}}\right)$

Triethylene glycol (75.1 g., 0.50 mole) and succinic anhydride (100 g., 1.00 mole) were used. The product crystallized after one week at $5^{\circ}(166.6 \mathrm{E} ., 95 \%)$. It was purified by recrystallization from an ethyl acetate-hexane mixture, m.p. $60-62^{\circ}$; ir: 1725,1690 , $1185 \mathrm{~cm}^{-1}$; nmr: $(\delta) 2.68\left(\mathrm{~s}, 8 \mathrm{H}, \mathrm{OCCH}_{2} \mathrm{CH}_{2} \mathrm{COOH}\right), 3.67$ (s and $t, 8 \mathrm{H}$, $\left.\mathrm{CH}_{2} \mathrm{OCH}_{2}\right), 4.30\left(t, 4 \mathrm{H}, \mathrm{COOCH}_{2}\right), 10.57(\mathrm{~s}, 2 \mathrm{H}, \mathrm{COOH})$. Molecular 
weight: Calcd: 350.4. Found: 365. A satisfactory elemental analysis was obtained via its derivatives, compounds 2 and 5 .

Oxydiethylene bis(Hydrogenmaleate) (12).

Diethylene glycol (106 g., 1.00 mole) and maleic anhydride (196 g., 2.00 mole) were used. The product ( 300 g., 99\%) was dissolved in $500 \mathrm{ml}$. of an aqueous sodium bicarbonate solution and extracted with $500 \mathrm{ml}$. of chloroform. The aqueous solution was then acldified with dilute hydrochloric acid and extracted with chloroform. The purified product was a viscous Iiquid;

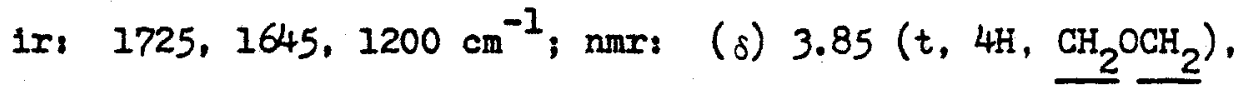
$4.45\left(t, 4 \mathrm{H}, \mathrm{COOCH}_{2}\right), 6.45(\mathrm{~s}, 4 \mathrm{H}$, vinyl hydrogens), $10.75(\mathrm{~s}$, 2H, $\mathrm{COOH}$ ). Molecular weight: Calcd: 302.3. Found: 325. A satisfactory elemental analysis was obtained via its derivative, compound ?.

Oxydlethylene bis(Hydrogencitraconate) (13).

Diethylene glycol (84.0 g., 0.37 mole) and citraconic anhydride $(40.0 \mathrm{~g} ., 0.75$ mole) were used. The product $(62.0 \mathrm{~g}$. , 51\%) was purified as reported above for compound 4 to give a viscous liquid; ir: $1725,1650,1200 \mathrm{~cm}^{-1}, \mathrm{nmr}$ ( $\delta 2.10\left(\mathrm{~s}, 6 \mathrm{H}, \mathrm{CH}_{3}\right)$, $3.70\left(t, 4 \mathrm{H}, \mathrm{CH}_{2} \mathrm{OCH}_{2}\right), 4.35\left(t, 4 \mathrm{H}, \mathrm{COOCH}_{2}\right), 5.95(\mathrm{~s}, 2 \mathrm{H}$, vinyl hydrogen $), 9.30,(\mathrm{~s}, 2 \mathrm{H}, \mathrm{COOH})$, also small peaks at 2.25 and 6.85 . Molecular weight: Calcd: 330.0. Found: 346. A satisfactory elemental analysis was obtained via its derivative, compound 8 . 
IN, N'-Ethylenedisuccinimaic Acid $\left(\frac{1}{2} 2^{4}\right)$

Ethylenediamine ( $30 \mathrm{~g} ., 0.50 \mathrm{~mole})$ and succintc anhydride (100 g., 1.00 mole) were used. The product (125.1 g., 96\%, was recrystallized from $95 \%$ ethanol which contained about $2 \%$ of $6 \mathrm{~N}$ hydrochloric acid; m.p. 159-161 ${ }^{\circ}$; ir: $3300,1690,1640,1550 \mathrm{~cm}^{-1}$; $\mathrm{nmr}$ (deuterium oxide): ( $\delta$ ) $2.68\left(2 \mathrm{t}, 8 \mathrm{H}, \mathrm{OCCH}_{2} \mathrm{CH}_{2} \mathrm{COCH}\right), 3.36(\mathrm{~s}$, $\left.4 \mathrm{H}, \mathrm{CONHCH}_{2}\right)$.

Anal. Calcd. for $\mathrm{C}_{10} \mathrm{H}_{16}{ }^{\mathrm{O}} 6^{\mathrm{N}} 2$ : C, 46.15; H, 6.20; $\mathrm{N}, 10.76$. MW, 260.2. Found: C, 46.06; H, 6.25; N, 10.68; MW, 270.

$\underline{N}, \underline{N^{\prime}}$-Ethylene bis $(\underline{N}-$ Methylsuccinamic Acid) $(\underset{2 n}{15})$

sym-Dimethylethylenediamine ( 5 E., 0.057 mole) and succinic anhydride $(11.35 \mathrm{~g} ., 0.114 \mathrm{~mole})$ were used. The product (17 g., 99\%) was recrystallized from 95\% ethanol which contained about $2 \%$ of $6 \underline{\mathrm{N}}$ hydrochloric acid, m.p. 130-132\%; Ir: 1740, 1620, 1510

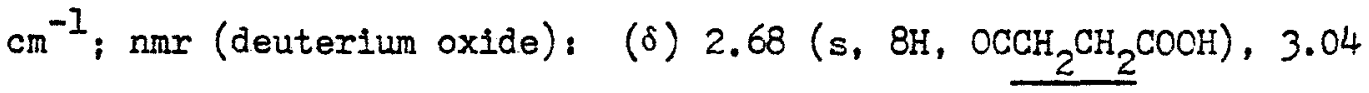
(m, $\left.6 \mathrm{H}, \mathrm{NCH}_{3}\right), 3.64\left(\mathrm{t}, 4 \mathrm{H}, \mathrm{CONCH}_{2}\right)$.

Anal. Calcd. for $\mathrm{C}_{12} \mathrm{H}_{20}{ }^{\mathrm{O}} 6^{\mathrm{N}} 2^{\prime} \mathrm{C}, 49.99 ; \mathrm{H}, 6.99 ; \mathrm{N}, 9.72$; MW, 288.3. Found: C, 49.91; H, 7.04; N, 9.87; MW, 288. $\gamma, \gamma \cdot-D 10 \times 0-1,4-p i p e r a z i n e d i b u t y r i c$ Acid $(26)$.

Piperazine (2l.5 g., $0.25 \mathrm{~mole})$ and succinic anhydride (50 E., 0.50 mole) were used. The product $(54.5 \mathrm{~g} ., 76 \%)$ was recrystallized from hot ethanol, m.p. $156.6-158.5^{\circ}$; 1r: 3000,1720 ,

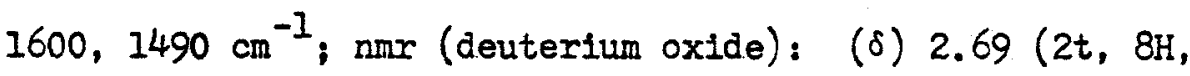
$\left.\mathrm{OCCH}_{2} \mathrm{CH}_{2} \mathrm{COOH}\right), 3.68\left(t, 8 \mathrm{H}, \mathrm{CONCH}_{2}\right)$. 
Anal. Calcd. For $\mathrm{C}_{12} 2^{\mathrm{H}} 18^{\mathrm{O}} 6^{\mathrm{N}} 2^{2} \quad \mathrm{C}, 50.35 ; \mathrm{H}, 6.34 ; \mathrm{N}, 9.78$; MW, 286.5. Found: C, 50.14; H, 6.41; N, 9.93; MW, 280. 2-(3-Carboxy-N-methylpropioamido) ethyl Hydrogensuccinate ( 17 ).

2-(Methylamino)ethanol (18.76 g., 0.25 mole) and succinic anhydride $(50 \mathrm{~g} ., 0.50$ mole $)$ were used. The product $(68.3 \mathrm{g.}$, 99\%) was a viscous Iiquid; ir: $1740,1620,1510 \mathrm{~cm}^{-1}$; $\mathrm{nmr}$ $2.69\left(2 \mathrm{t}, 8 \mathrm{H}, \mathrm{OCCH}_{2} \mathrm{CH}_{2} \mathrm{COOH}\right), 3.05\left(2 \mathrm{~d}, 3 \mathrm{H}, \mathrm{NCH}_{3}\right), 3.68(\mathrm{t}, 2 \mathrm{H}$, $\left.\mathrm{CONCH}_{2}\right), 4.28\left(t, 2 \mathrm{H}, \mathrm{COOCH}_{2}\right), 9.90(\mathrm{~s}, \mathrm{IH}, \mathrm{COOH}), 10.57(\mathrm{~s}, 1 \mathrm{H}$, $\mathrm{COOH}$ ).

Anal. Calcd. for $\mathrm{C}_{11} \mathrm{H}_{17} \mathrm{O}_{7} \mathrm{~N}:$ C, 48.00; H, 6.23; N, 5.09; MW, 277.3. Found: C, 47.85; H, 6.36; N, 5.21; MW, 275. Thiodiethylene bis(Hydrogen succinate) $(\underset{2}{(18})$.

Thiodiethylene glycol ( $30.55 \mathrm{~g} ., 0.25$ mole) and succinic anhydride $(50 \mathrm{~g} ., 0.50 \mathrm{~mole})$ were used. The product $(30.7 \mathrm{g.,}$ 38\%) was recrystallized from ethanol, m.p. dec. $>120^{\circ}$; ir: 1720 , $1160 \mathrm{~cm}^{-1} ; \mathrm{nmr}:(\delta) 2.70\left(\mathrm{~s}, 8 \mathrm{H}, \mathrm{OCCH}_{2} \mathrm{CH}_{2} \mathrm{COOH}\right), 2.86(t, 4 \mathrm{H}$, $\left.\mathrm{CH}_{2} \mathrm{SCH}_{2}\right), 4.30\left(t, 4 \mathrm{H}, \mathrm{COOCH}_{2}\right), 7.85(\mathrm{~s}, 2 \mathrm{H}, \mathrm{COOH})$. Molecular weight: Calcd: 322.3. Found: 326.

Oxybls(ethyleneoxyethylene) bis(Hydrogenglutarate) $(\underset{\sim}{19})$.

Tetraethylene glycol (194 g., $1.00 \mathrm{~mole}$ ) and glutaric anhydride (228.2 g., 2.00 mole) were used. The product (400 g.,

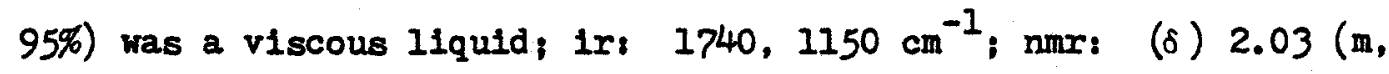
$\left.4 \mathrm{H}, \mathrm{CH}_{2} \mathrm{CH}_{2} \mathrm{CH}_{2}\right), 2.48\left(t, 8 \mathrm{H}, \mathrm{CH}_{2} \mathrm{CH}_{2} \mathrm{CH}_{2}\right), 3.66$ (s and $t, 12 \mathrm{H}$, $\left.\mathrm{CH}_{2} \mathrm{OCH}_{2}\right), 4.28\left(\mathrm{t}, 4 \mathrm{H}, \mathrm{COOCH}_{2}\right), 10.32(\mathrm{~s}, 2 \mathrm{H}, \mathrm{COOH})$. 
Anal. Calcd. for $\mathrm{C}_{18} \mathrm{H}_{30} \mathrm{O}_{11}$ : C, 51.18; H, 7.16; MW, 422.4 . Found: C, 50.98; H, 7.12; MW, 448.

Macrocyclic Compounds.

1,4,9,12-Tetraoxacyclohexadecane-5,8,13,16-tetrone (1).

Succinyl chloride $(15.0 \mathrm{~g} ., 0.097 \mathrm{~mole})$ and ethylene glycol (6.0 g., 0.097 mole) were used. The viscous product (19.0 g., 68\%), was purified by alumina chromatography and partially crystallized upon standing; irl $1740 \mathrm{~cm}^{-1}$; nmr: $(\delta) 2.70(\mathrm{~s}, 8 \mathrm{H}$, $\left.\mathrm{COCH}_{2} \mathrm{CH}_{2} \mathrm{CO}\right), 4.34\left(\mathrm{~s}, 8 \mathrm{H}, \mathrm{COOCH}_{2}\right)$.

Anal. Calcd. for $\mathrm{C}_{12}{ }^{\mathrm{H}} 16^{\mathrm{O}} 8^{8}$ C, $50.00 ; \mathrm{H}, 5.60 ; \mathrm{MW}, 288.3$. Found: C, 49.82; H, 5.62; MW, 286. $1,4,7,10,15,18$-Hexaoxacyclodocosane-11, 14,19,22-tetrone $\underset{\sim}{(2)}$.

Ethylenebis(oxyethylene bis(hydrogensucclnate) dichloride from $\frac{11}{\sim \Omega}(15.48 \mathrm{~g} ., 0.04 \mathrm{~mole})$ and ethylene glycol (2.73 g., 0.04 mole) were used. The viscous product $(0.20 \mathrm{~g}, 0.5 \%)$ was purified

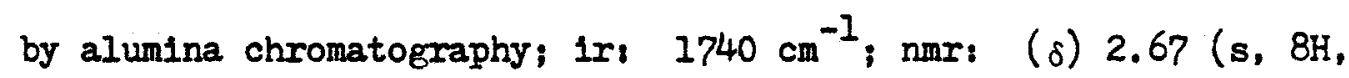
$\left.\mathrm{COCH}_{2} \mathrm{CH}_{2} \mathrm{CO}\right), 3.67\left(\mathrm{~s}, 4 \mathrm{H}, \underline{\mathrm{CH}_{2} \mathrm{OCH}_{2}}\right), 3.73\left(\mathrm{t}, 4 \mathrm{H}, \mathrm{COOCH}_{2} \mathrm{CH}_{2} \mathrm{O}\right), 4.26$ $\left(t, 4 \mathrm{H}, \mathrm{COOCH}_{2}\right), 4.33\left(\mathrm{~s}, 4 \mathrm{H}, \mathrm{COOCH}_{2} \mathrm{CH}_{2} \mathrm{OOC}\right)$.

Anal. Calcd. for $\mathrm{C}_{16} 6_{24}{ }^{\mathrm{O}} 10^{\prime}$ C, 51.05; H, 6.44; MW, 376.4 Found, C, 50.72; H, 6.60; MW, 352 .

1,4-Dioxa-9,12-diazacyclohexadecane-5,8,13,16-tetrone (3).

Ethylene bis(hydrogensuccinate) dichloride from $2(13.69 \mathrm{~g} .$, 0.05 mole) and excess ethylene diamine $(6.0 \mathrm{~g} ., 0.1$ mole $)$ were used. 
The product $(6.0 \mathrm{~g} ., 46 \%)$ was extracted and recrystallized from chloroform, m.p. $190-192^{\circ}$; ir: $3300,3120,1725,1640,1560 \mathrm{~cm}^{-1}$; $\mathrm{nmr}$ (deuterium oxide): (s) $2.64\left(\mathrm{~m}, 8 \mathrm{H}, \mathrm{COCH}_{2} \mathrm{CH}_{2} \mathrm{CO}\right), 3.38(\mathrm{~s}, 4 \mathrm{H}$, $\left.\mathrm{NHCH}_{2} \mathrm{CH}_{2} \mathrm{NH}\right), 4.39\left(\mathrm{~s}, 4 \mathrm{H}, \mathrm{COCCH}_{2} \mathrm{CH}_{2} \mathrm{OOC}\right)$.

Anal. Calcd. for $\mathrm{C}_{12} \mathrm{H}_{18} \mathrm{~N}_{2}^{\mathrm{O}} ; \mathrm{C}, 50.38 ; \mathrm{H}, 6.30 ; \mathrm{N}, 9.78$; MW, 286.3. Found: C, 50.10; H, 6.19; N, 9.65; MW, 280. 1,4,7-Trioxa-12,15-diazacyclononadecane-8,11, 16,19-tetrone $(\underset{2}{4})$.

Oxydiethylene bis(hydrogensuccinate)dichloride from in $(34.3 \mathrm{~g} ., 0.1 \mathrm{~mole})$ and excess ethylene diamine $(12.6 \mathrm{~g} ., 0.21$ mole) were used. The product $(2.69 \mathrm{~g}$, , 8\%) was extracted and recrystallized from chloroform, m.p. $167-168^{\circ}$; ir: 3300,3100 ,

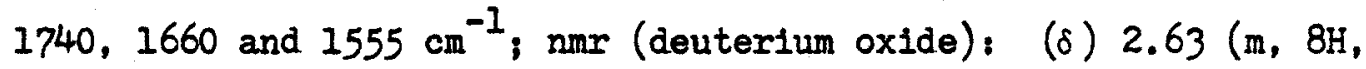
$\left.\mathrm{COOCH}_{2} \mathrm{CH}_{2} \mathrm{CONH}\right), 3.35\left(\mathrm{~s}, 4 \mathrm{H}, \mathrm{NHCH}_{2} \mathrm{CH}_{2} \mathrm{NH}\right), 3.80\left(t, 4 \mathrm{H}, \mathrm{CH}_{2} \mathrm{OCH}_{2}\right)$, $4.28\left(t, 4 \mathrm{H} \mathrm{COOCH}_{2}\right)$.

Anal. Calcd, for $\mathrm{C}_{14} \mathrm{H}_{22} \mathrm{~N}_{2} \mathrm{O}_{7} \cdot 3 \mathrm{H}_{2} \mathrm{O}: \mathrm{N}, 7.29$; MW, 384. Found, N, 7.23; MW, 350 .

$1,4,7,10$-Tetraoxa-15,18-diazacyclodocosane-11, 14,19,22-tetrone $\underset{n}{(5)}$.

Ethylenebis(oxyethylene) bis(hydrogensuccinate) dichloride from $I_{\sim}(38.2 \mathrm{~g}, 0.10 \mathrm{~mole})$ and excess ethylenediamine (12.6 g., 0.21 mole) were used. The product ( $3.74 \mathrm{g.}, 10 \%)$ was extracted and recrystallized from chloroform, m.p. $159-161^{\circ}$; ir: 3300 , $3100,1725,1640,1550 \mathrm{~cm}^{-1} ; \mathrm{nmr}(\delta) 2.63\left(\mathrm{~m}, 8 \mathrm{H}, \mathrm{COCH}_{2} \mathrm{CH}_{2} \mathrm{CO}\right)$, $3.44\left(\mathrm{~m}, 4 \mathrm{H}, \mathrm{NHCH}_{2} \mathrm{CH}_{2} \mathrm{NH}\right), 3.70\left(\mathrm{t}, 8 \mathrm{H}, \mathrm{CH}_{2} \mathrm{OCH}_{2}\right), 4.30(t, 4 \mathrm{H}$, $\left.\mathrm{COOCH}_{2}\right), 6.62(\mathrm{~s}, 2 \mathrm{H}, \underline{\mathrm{NH}})$. 
Anal. Calcd. for $\mathrm{C}_{1} 6^{\mathrm{H}} 26^{\mathrm{N}}{ }_{2} \mathrm{O}_{8}:$ C, $51.33 ; \mathrm{H}, 7.00 ; \mathrm{N}, 7.48$; MW, 374.4. Found: C, 51.08; H, 7.16; N, 7.28; MW, 399.

4-Benzyl-1, 7,12,15-tetraoxa-4-azacyclononadecane-8,11, 16, 19-tetrone (6).

Ethylene bis(hydrogensuccinate) dichloride from 2 (29.9 g., 0.1 mole) and $2,2^{\prime}$-(benzylimino)diethanol (14.1 g., 0.07 mole) were used. The product $(1.5 \mathrm{~g} ., 5 \%)$ was purified by alumina chromatography; ir: $1740 \mathrm{~cm}^{-1} ; \mathrm{nmr}$ ( $(\delta) 2.63\left(\mathrm{~d}, 8 \mathrm{H}, \mathrm{COCH}_{2} \mathrm{CH}_{2} \mathrm{CO}\right), 2.78(\mathrm{t}, 4 \mathrm{H}$, $\left.\mathrm{NCH}_{2} \mathrm{CH}_{2} \mathrm{O}\right), 3.68\left(\mathrm{~s}, 2 \mathrm{H}, \mathrm{PhCH}_{2} \mathrm{~N}\right), 4.13\left(\mathrm{t}, 4 \mathrm{H}, \mathrm{NCH}_{2} \mathrm{CH}_{2} \mathrm{O}\right), 4.30(\mathrm{~d}, 4 \mathrm{H}$, $\left.\mathrm{COOCH}_{2} \mathrm{CH}_{2} \mathrm{COO}\right), 7.26$ (s, 5H, aromatic).

Anal. Calcd. for $\mathrm{C}_{21} \mathrm{H}_{27} \mathrm{NO}_{8} \cdot 2 \mathrm{H}_{2} \mathrm{O}: \mathrm{N}, 3.06 ; \mathrm{MW}, 457$. Found: $N, 3.20 ; \mathrm{MW}, 454$.

$1,4,7,12,15,18$-Hexaoxacyclodocosa-9,20-diene-8,11,19,22-tetrone (7). Oxydiethylene bis(hydrogenmaleate) dichloride from $12(7.5$ g., 0.02 mole) and diethylene glycol (2.34 g., 0.02 mole) were used. The product $(1.32 \mathrm{~g} ., 16 \%$ ) was recrystallized from $100 \%$ ethanol, m.p. $127.5-128^{\circ}$; ir: $1720 \mathrm{~cm}^{-1}$; $\mathrm{nmr}$ ( $(\delta) 3.76\left(t, 8 \mathrm{H}, \mathrm{CH}_{2} \mathrm{OCH}_{2}\right)$, $4.45\left(t, 8 \mathrm{H}, \mathrm{COOCH}_{2}\right), 6.95(\mathrm{~s}, 4 \mathrm{H}$, vinyl $\mathrm{H})$.

Anal. Calcd. for $\mathrm{C}_{16} \mathrm{H}_{20} \mathrm{O}_{10}$ C, $51.64 ; \mathrm{H}, 5.37 ; \mathrm{MW}, 372$. Found, C, 51.45; H, 5.50; MN, 389 .

9,21-Dimethy1-I,4,7,12,15,18-hexaoxacyclodocosa-9, 20-diene-8, 11,19,22tetrone $(\underset{2}{8})$.

Oxydlethylene bis(hydrogencitraconate) dichloride from 13 (2I g., 0.06 mole) and diethylene glycol ( $5.0 \mathrm{~g} ., 0.05$ mole) were used. The product $(0.11 \mathrm{~g} ., 1 \%)$ was purified by alumina chromatography; 
Ir: $1720 \mathrm{~cm}^{-1} ; \mathrm{nmr}:(\delta) 2.05\left(\mathrm{~s}, 6 \mathrm{H}, \mathrm{CH}_{3}\right), 3.70\left(\mathrm{~m}, 8 \mathrm{H}, \mathrm{CH}_{2} \mathrm{OCH}_{2}\right)$,

$4.32\left(\mathrm{~m}, 8 \mathrm{H}, \mathrm{COOCH}_{2}\right), 5.90(\mathrm{~s}, 2 \mathrm{H}$, vinyl $\mathrm{H})$, also small peaks at 2.27 and 6.83 .

Anal. Calcd. for $\mathrm{C}_{18} \mathrm{H}_{24} \mathrm{O}_{10}$ : C, 53.99; H, 6.04; MW, 400 . Found: C, $53.80 ; \mathrm{H}, 6.06$; MH, 388 .

Acknowledgements.

Th1s work was partially supported by National Science Foundation Grant CHE 76-10991 and National Institute of Health Grant GM-18811-04. A research grant to S. F. N. from the Associated Students of Brigham Young University is also acknowledged. 


\section{REFERENCES AND NOTES}

(1) Presented at the Fall Semiannual Meeting of the Utah Academy of Sclence, October 1976.

(2) Inquiries should be sent to $\mathrm{Dr}$. Jerald S. Bradshaw.

(2) J. J. Christensen, D. J. Eatough, and R. M. Izatt, Chem. Rev.. 74,351 (1974).

(4) R. M. Izatt, D. J. Eatough, and J. J. Christensen, Struc. Bonding (Eerlin), 16, 161 (1973).

(5) R. M. Izatt, R. E. Terry, B. I. Haymore, I. D. Hansen, N. K. Dalley, A. G. Avondet, and J. J. Christensen, I. Am. Chem. Soc., 98, 7620 (1976).

(6) R. M. Izatt, R. E. Terry, D. P. Nelson, Y. Chan, D. J. Eatough, J. S. Bradshaw, L. D. Hansen, and J. J. Christensen, ibid.. 28, 7626 (1976).

(7) Yu. A. Ovchinnikov, V. T. Ivanov, and A. M. Shkrob, Membrane Active Complexones", Elsevier, New York, 1974.

(8) S. E. Dewes and P. C. Coleman, J. Chem. Soc., Perkin Trans. I, 2148 (1972).

(9) S. E. Dewes and B. G. Riphagen, ibid., 323 (1974).

(10) S. E. Dewes and B. G. Riphagen, ibid., 1908 (1974).

(11) J. S. Bradshaw, I. D. Hansen, S. F. Nielsen, M. D. Thompson, R. A. Reeder, R. M. Izatt, and J. J. Christensen, J. Chem. Soc., Chem. Commun., 874 (1975). 
(12) J. S. Bradshar, C. T. Bishop, S. F. Nielson, R. E. Asay, D. R. K. Masihdas, E. D. Flanders, I. D. Hansen, R. M. Izatt, and J. J. Christensen, J. Chem. Soc. Perkin Trans. I, in press.

(13) W. R. DePierr, Jr., and H. L. Wilder, U. S. Patent 3,639,376, Feb. 1, 1972; Chem. Abstr., 26, 14154p (1972).

(14) A. I. Suvarov and T. A. Perlyaeva, Trans. Inst. Khim., Akad. Nauk SSSR, Ural Titial, 44 (1971).

(15) See for example, T. Hino and T. Sato, Chem. Pharm. Bul1, 22, 2866 (1974).

(16) R. Buyle, Helv. Chim. Acta., 49, 1425 (1966).

(17) H. Matsuda and S. Waizumi, Japanese Patent 7,036,731.

(18) R. A. Spragg, J. Chem. Soc., (B), 1128 (1968).

(19) Y. Miron, B. R. McBarvey and H. Moraivety, Macromolecules, 2 , 154 (1969).

(20) C. A. Buehler and D. E. Pearson, "Survey of Organic Synthesis," Wiley Interscience, New York, 1970, p. 860.

(21) C. J. Pedersen, I. Am. Chem. Soc., 89, 7017 (1967). 
The Synthesis of Novel Macrocyclic Multidentate Compounds from Dioxodioic Acids (1)

\title{
R. I Amy, J. S. Bredchaw (2), S. F. Nielsen, M. D. Thompeon, J. W. Snow,
} D. R. K. Masihdas, R. M. Izett, and J. J. Christensen

Departments of Chemietry and Cheraical Engineerine, and Contribution No. 96 from the Thermechtmieal Institute. Brigham Youns University. Prova, Utah 84602

Reveived Oetober 29, 1976

\begin{abstract}
A series of novel macrocyclic multidentate crown compounds have been prepared from a series of dioxodioic acids. The dioxodioic acidis were prepuned by treating various oligoethylene slycols or amines with maleic, succinic, citraconic, and glutaric anhydrides. The crown compounda were then synthesized from the dioxodioic acid chlorides obtained from the diacids and various oligoethylene glycols or ethylene diamine. The following macrocyclic compounds have been prepared: 1,4,9,12-tetraoxacyclohexadecane-5,8,13.16-tetrone (1): 1,4,7,10,15,18berseoracyclodocosene-11,14,19,22-tetrone (2); 1,4-dioxa-9,12-diazacyclohexadecane-5,8,13,16 tetrone (3); 1,4,7-trioxa-12.15-diazacyclonoadecene-8,11,16,19-tetrone (4); 1,4,7,10-tetraoxa15,18-diazacy clodocosene-1 1,14,19,22-tetrone (5); 4benzy -1,7,12,15-tetraoxa-t-azacyclonoma . decane-8,11,16,19-tetrone (6); 1,4,7,12,15,18-hexaoxacyclodoeose-9,20-diene-8,11,19,22. tetrone (7); and 9,21-dimethyl-1,4,7,12,15,18-hexaoxacy clodocosa-9,20-diene-8,11,19,22-tetrone (B) (Figure 1).
\end{abstract}

\section{J. Hetwoeryetic Chem, 14.85 (1977).}

The cation complexing properties of ayclic polyethers have been studied extensively (3-6), and have been found. in certain instances, to resemble those of the cyclic antibiotics valinomycin and nonactin (0). The availability of synthetic cyclic polyethers and related compounds makes possible a systematic study of the factors which determine complex stability and which affect cation selectivity by macrocyclic compounds. One objective of our research program is to prepare and study a series of multidentate compounds which resemble naturally oceuring macrocyclic compounds.

This work reports the synthesis of the foilowing corn. pound containing multiple ester and amide moietie in addition to ether groups (3-6) (see figure 1). These compounds include 1,4,9,12-tetraoxacyeiohexedecane $5,8,13,16$-tetrone (1): $1,4,7,10,15,18$-hexaoxacyclodocosene-11,14,19,22-tetrone (2); 1,4-dioxa-9,12-diazayclohexadecane-5,8,13,16-tetrone (3); $1,4,7$-trioxa12,15-diazacyclononadecane-8,11,16,19-tetrone (4); $1,4,7,10$-tetreo xa-15,18-diazucy clodocosane-11,14,19,22tetrone (5): 4-benxyl-1,7,12.15-tetroxa-t-wacyctononadecane-8,11,16,19-tetrone (6); $1,4,7,12,15,14$-hexaoxaoyelodocose-9,20-diene-8,11,19,22-tetrone (7); and 9,21dimethyl-1,4, $, 12,15,18$-hexaoxacy clodocosa-9,20-die ne8,11,19,22-tetrone (8) (Figure 1). Also included is a report of the syathesic of a series of dioxodioic acids

needed for the production of these maerocyclic compounds.
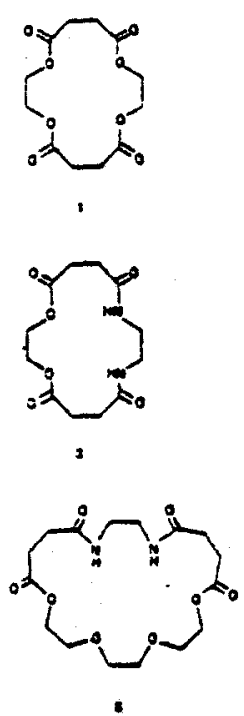<smiles>O=C1CCC(=O)OCCOC(=O)CCC(=O)OCCOCCOCCO1</smiles><smiles>NC(=O)CCCC(=O)NCCC(=O)OCCOCCOC(=O)O</smiles> 
D. R. K. Masihdas, R. M. Izatt, and J. J. Christensen

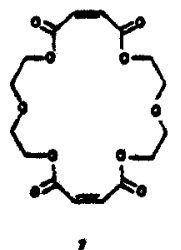

The synthesis of macroeyclic esters las been reported previously. Dewes and coworkens $(8-10)$ have prepared several similar compounds which contain a number of diand tetraesters from phithalie and maieic acid systerns. They prepared eyclic ester compounds from the reaction of dipolassium salts of phthalic or maleic acid with a series of alkyl and alkynyl dibromides to make 10.34 membered ring compounds. Their compounds, however, did not contain the ethylene oxide moiety. We recently reported the synthesis of crown ether-esters which have one diacid moiety (11.12). but the synthesis of crown ether-eaters containing two diacid moieties has not been reported.
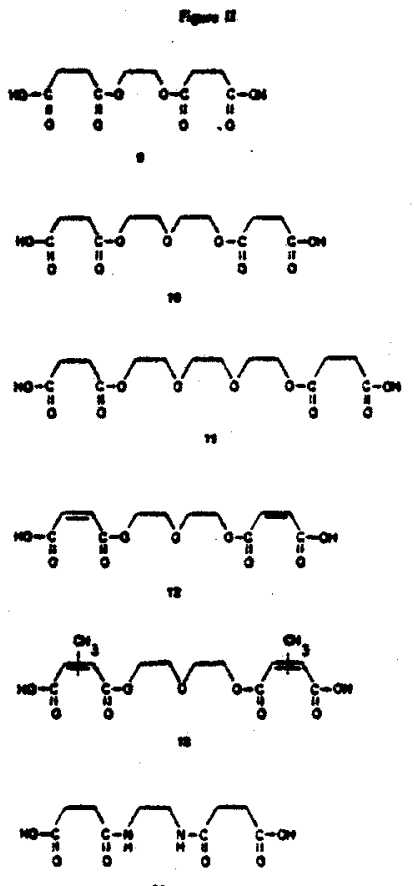
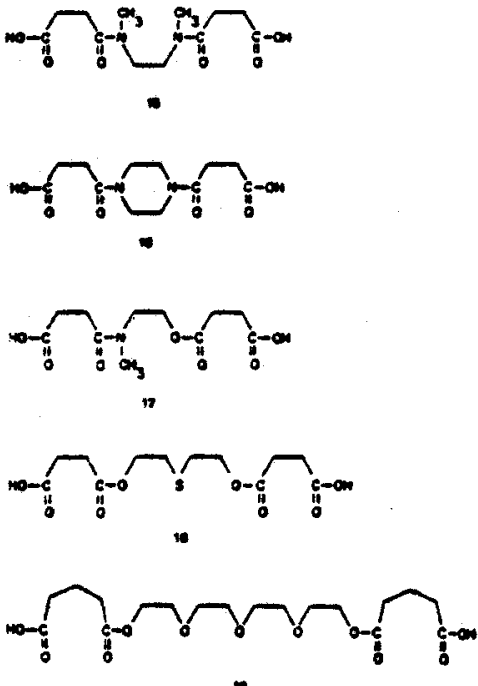

Preparation of Starting Materials

The dioxodioic acids needel for thia study were prepared by treating various oligoethylene glycols with succinic, maleic, and citraconic anbydriles. The following compounds have been prepared: ethylene bis(hydrogen suecinate) (9); oxydiethylene bir(hydrogen succinate) (10); ethylenebis(oxyethylene) bis(hyilogen succinate) (11); oxydiethylene bis(hyrlrogen maleute) (12); and oxydiethylene bis(hydrogen citraconate) (13). Related dioic acids prepared from various diamines and glvcols and succinic or glutaric anhyriride are also reported in this paper. These include: $N_{,} V^{\prime}$ ethylenertisuccinamic acid (14); $N, N^{\prime}$ ethylene-bis( $N$-methylsuceinamic acid) (15): $\gamma, \gamma^{\prime}$-dioxo-1,4-piperazinedibutyric acid (16): 2-(3-carboxy $-N$-methylpropionamido)ethyl hydrogen succinate (17); thiodiethylane bis(hydrogen succinate) (18): and oxybia(ethyleneoxyethylene) bix (hydrogen giutarate) (19).

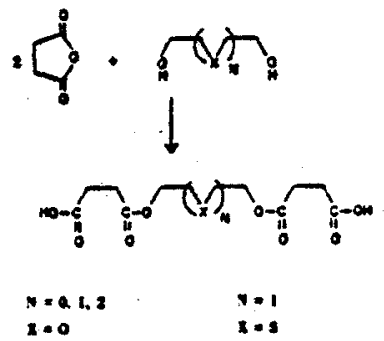




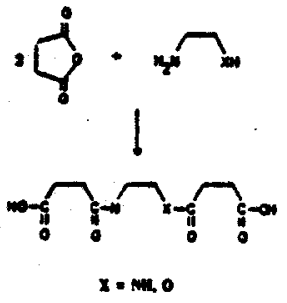

Results and Discussions

The formation of compotunts 9 and 10 have been reported previously from the glveots and succinic acid: however, no physical constants were given (13). Esterification of glycols with various acids such as terephthalic, fumaric and succinic have also been presenteri. These products contained one acid group (14). Dinic acids containing amide functions have not been reported al. though 2,6-piperazine dicarboxylic acids are knuwn (15). Compounds somewhat similar to these have abo been reported by other workers (16.17).

The structures proposed for the dioxodioic acid compounds are consistent with those determined from the nur and ir spectra, elemental anaiysis of the products or a macrocyclic derivative, and molecular wright determinations. The diucids containing the ester moieties all exhibited an ir band at $1730-1740 \mathrm{~cm}^{-1}$ and a band at $1690-1720 \mathrm{~cm}^{-1}$ indicative of the ester and carboxylic acid eatonyl groups. respectively. Those compounds poencessing the amide function $(1+17)$ all contained bands at $1620-1600$ and $1550.1500 \mathrm{~cm}^{-1}$ indicative of the amide group as well as the ester carbonyl band at 1710 . $1,40 \mathrm{~cm}^{-1}$.

The nmr spectra of the compounds are most revealing. The ethylene hydroyens for the succinic acid portions for all acids derived from succinic anhydricie $(9,11,14$. $15,18,17$, and 18) exhibited nme pesks at $2.68 \pm 0.02$ $\delta$ with the exception of compound 10 which exhibited a peak at 2.556 . The gtutarate pongylene hydroxens of compound 19 exhibited a triplet peak at $2.48 \delta$ and a multiplet at 2.035 . The unsaturated compounds 12 and 13 exhibited the usual vinyl hydrogen peaks in the nmr apectre. All ester methylene hydrogens sppeared at $435 \pm 0.10 \&$ while the ether methyleue hydrogens appeared at $3.70 \pm 0.10 \delta$ in the nur spectra. The hydrogens on the carbon next to sulfur on compound 18 exhibited a peak at $2.86 \delta$.

The amide diacids (14-17) exhibited the expected nme peake. For compound 16. the amide methylene peaks occured as a triplet at 3.68 \& with small triplet peaks appearing at $3.40 \delta$ and $3.88 \delta$ as weil, whose total peak area (3.40-3.88 $\delta$ ) equals eight hỵtrogens. Sprugg, in an non study of N,N-disubutituted piperazine derivatives, found cis, trans-isomers with the erans form constituting the major product (18). Linuaven splitting of the metlyl peake from compoumble 15 and 17 were also observed in the nur at 3.04 and 3.068 , reapectively. Mlinon and coworkess also noted such splitting of Vilie groups in arvide moieties of polymers which they attributed to hindered cotation about the amide bond (19).

Compounds 9.13 can be easily transformed into the corresponding diacid ehlorides by the action of thionyl chloride. The acid chloritles were then used to form the macrocyclic compounds. Diacid chlorides for compounds 14-18 cannot be formed by the action of thionyl chloride due to the destruction of the amide function within the diacid (20). For example, when compound i4 was treated with thionvl chloride, a cyano bond was ubserved in an ir of the reaction mixture. Metal complexation studies of these diarids are presently being undertaken and will be reported in a luture paper.

The novel macrocyclic compounds shown in Figure $I$ were prepared by treating the appropriate glvcol or ethylene diamine with diucid chlorides prepared from the appropriate dioxodioic acid.
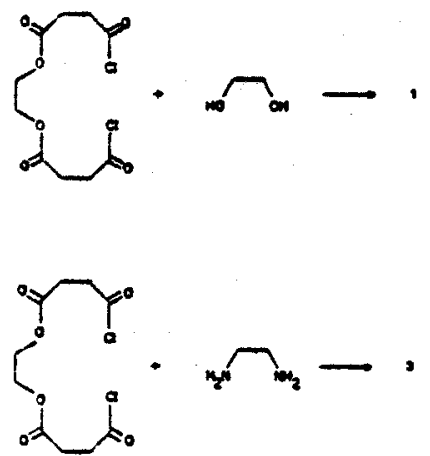

The structures proposed for these compounds are consistent with those determined trom the ir and $\mathrm{nmr}$ spertr. molecular weight determinations. and elementul analyses. Thexe macrosyclic compounds exhibited it peaks comparable in some rexpects to the diacids from which thev were derivell. The ester muieties all exhibited an if band at 1720.1740 $\mathrm{cm}^{-1}$ and the amile moieties all exhibited bands at $1660.1640 \mathrm{~cm}^{-1}$ and 1560.1550 $\mathrm{cm}^{-1}$.

The nrme spectra also are comparable to the diacids. The ethylene hydrogens for the succinic acid moieties of compounds $(1-6)$ exhibitert nimr peaks at $2.6 .5=0.02 \delta$. All ester methylene hydrogen appeared at $4.30 \pm 0.10 \delta$ while the ether methylene hydrogens appeared at $3.50 \pm$ 0.108 . Mrthylene hydmgens next to nitrogen exhibited nmr peaks at $3.33 \pm 0.10 \delta$. The vinyl hydrogens of 
compounds 7 and 8 exhibited peaks at $6.90 \pm 0.10 \delta$.

Yields for these crown compounds ranged from 1 to 68\%. The low yields were a result of the difficulty in parification of the diacid chlorides before reaction with the appropriate glycol. Several of the compounds which were colide exhibited water penks in ir spectra; however, after vacuum drying, these pealis were greatly reduced of remowed entirely. Work is now in progress to determine the complexation properties of these compounds.

\section{EXPERMENTAL}

All ir spectra were obtained on a Hilger and Wats H.1200 Infragaph. The nmr spectra were obtained on a Varian EM-390 apetrometer. The elemeatal analyain were periormed by Galbraith Luboratoriea, Knoxville. Tennessee. The molecular weidht deter. minutions for the diacids were performed either by a base titration or on a Hitachi PeckinElmer 115 Molecular Weight Apparatus Thoee for the macrocyclic compounds were done on the Hituchi PeskinElmer appantus. Meitins points are un. corrected.

Startion Matérials

Nost of the urting dyeols amine and anhydrides were und a purchesed: ethylene glyeol (Mallinekrodt), diethylene tyool (Eatman), triethylene glyeol (Bakes), 2,2' (benzylimino) diethanol (Praltz and Baver), ethylenedianine (MCB), piperazine (Aldrich), sym-dimethylethylenediamine (Aldrich), 2-(methyl. aminolethanel (Aldrich), thiodiethylene glycol (Fluka), swecinic salydride (Eactman), citracenic anhydride (Aldrich), maleic abydride (MCB), dutarie anhydride (Aldrich), suecinyl chloride (Aldrich).

General Synthed

The diacids were prepared by stowiy addin the gityeol of dismian to the anhydride in $500 \mathrm{ml}$. of benzene at $30^{\circ}$. The readting mixture was stired for at leat three davs. After the reaction wa stopped, the upper benzene layer was removed and the lower product layer was purified by recrystallization of by extruetion techniques. In the case of most anade compounda, the product solidified in the benzene. After benzene removal the erade product was recrystallized. Specifie details are piven for each of the diacid compounds.

The diacid chlorides from compounds 913 were prepared by sowly edding 0.4 mole of thionylethloride to the diacid (0.1 mole) in 1 lite of bereene and $\mathbf{2}$ mi. of pyridine. The resulting mixture was atired at room temperature for 2 houn. After the reaction we topped, the mixture wa filtered and the benzene was removed under ractum. The resulting lipuid product was nos further inoluted or eharacterized but wos uned direetly in the ratheis of the ranerocyelie exown compound.

A. maresyctie crown corapounds except compond 1 were propered by treating the dixcid chlorides from componuds 913 with the appropriate dyeol or sthylenedianine. The dyeol and diecid chloride each diwolved in 200 mh. of bemene or IIIF wore dowly added simultamemoly to $600 \mathrm{ml}$. of stiemet benzane at $50^{\circ}$. Exces ethylene diamine was added whre appropsiate 10 complex the hydrochlorie acjd generated during the reaction to avoid complexation in the amide containing erown compownda. The realiting mixture was stirred at $50-60^{\circ}$ for at least two days. After the reaction was stopped. bensene was mmoved under vacuum. The arede product wes then purified by veryutallication or by alumia chromageraphy using hexane with incresing anounts of chloroform at the efunat. Specific detaib are given for each crown compound.

Diacids.

Qthylewe bid(Hydroyenuctinate) (9.

Ethylene dyeal ( 31 e, 0.50 mole) and suecinie anhydride $(100$ a 1.00 mole) were used. The product $(127.71$ 2, 97.5\%) was recryatalliaed from an ethylacetate-hexane mixture, m.p. dec. $>80^{\circ}$; ir: 1740. 1705. $1170 \mathrm{~cm}^{-1}$; nme: (6) 268 (s. 8H. $\mathrm{OCCH}_{2} \mathrm{CH}_{2} \mathrm{COOH}$ ) 4.34 (s. $4 \mathrm{H}, \mathrm{COOCH}$ ) 9.93 (s, 2H, COOH). Molecular weight: Caled: 262.2. Found: 262.7. A satisfactory elemeatal analyis was obtained vis its derivatives, compounds 1, 3 and 6 .

Oxydiethylene bix (Hydrogenmecinate) (10).

Dirthylene glyeol (33 g-, 0.50 mole) and succinic anhydride $(100 \mathrm{~g} .1 .00 \mathrm{~mole})$ were used. The product $(127 \mathrm{~g}, 84 \%)$ was recrystallized from an athylacetate-trexane mixture: m.p. $70.72^{\circ}$; ir: 1720, 1680, $1180 \mathrm{em}^{-1}$; nur (deuterium oxide): (8) 2.66 (s. $\left.8 \mathrm{H}, \mathrm{OCCH}_{2} \mathrm{CH}_{2} \mathrm{COOH}\right), 3.64(\mathrm{t}, 4 \mathrm{H}, \mathrm{OCH}), 4.18(\mathrm{t}, \mathrm{H}$, OOC(CH$)_{2}$. Wolecular weight: Calcd: 306,3. Found: 256. I ativfactory etemental analysi wa oblained vi its derivative. compound 4

Ethylenabid (oxyethylene) bia(Hydrogenuceinate) (11).

Triethylene glycol (75.1 g- 0.50 mole) and stecinic anhydride $(100 \mathrm{~g} .1 .00$ mole) wer used. The product erystallized after one week at $3^{\circ}$ (166.6 g. 95\%). It was purifind by reerystallization from an ethyl acetate hex ane mixture, m. 60-62\%; ir: 1725. 1690. $1185 \mathrm{em}^{-1}$ : nnt: (5) 268 (s, 8H, OCCH$\left.{ }_{2} \mathrm{CH}_{3} \mathrm{COOH}\right)$. 3.67 (s and $\left.\mathrm{t}, \mathrm{BH}, \mathrm{CH}_{2} \mathrm{OCH}_{2}\right), 430(\mathrm{t}, 4 \mathrm{H}, \mathrm{COOCH}), 10.3 \mathrm{CH}^{\circ}$ (s) 3H. COOH. Molocular weight: Calcd: 350.4 Found: 365. A satiafactory elerwental analysis was obtrined vis its derivatives, comporind 2 and 5

Oxydiethylene bia(Hydrogenmaleate) (12).

Diethylene dyeol (106 g. 1.00 mole) and maleic anhydride (196 200 mole) were uned. The product $(300 \mathrm{~g} .99 \%)$ was diswolved in $500 \mathrm{~mL}$. of an aqueous sodium biearbonste solution and extracted with $500 \mathrm{mi}$. of ehloroiom. The aqueous solution was then acidified with dilute hydrochtoric acid and extracted with chloroiom. The purified product was a viscous hiquid: ir: $1725.1645,1200 \mathrm{~cm}^{-1}$; nmr: (6) 3.85 (t, 4H, $\mathrm{CH}_{2} \mathrm{OCH}_{2}$ ),

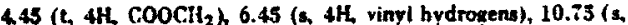
2H. $\mathrm{COOH}$. Sloleculat weinht: Caled: 302.3. Found: 325. A satisiectory elemental analyaie was obtained via its derivative, compound 7.

Oxydiathyieve bie(Hydrogencitreconate) (13)

Diethylene gtyeol (84.0 2, 0.37 mole) and citreconic anthydride (40.0 0.75 mole) were used. The product $(62.0 \mathrm{c} .51 \%)$ was puritied as reported above for compound 4 to give a viscous liquid: ir: 1725, 1650, $1200 \mathrm{em}^{-1}$; mar: (s) $2.10\left(\mathrm{~s}, 6 \mathrm{H}, \mathrm{CH}_{3}\right)$. 3.70 (t, $\left.4 \mathrm{H}, \mathrm{CH}_{2} \mathrm{OCH}_{2}\right), 4.35$ (t. $4 \mathrm{H} . \mathrm{COOCH}_{2}$ ), 5.95 (s, 2H. rimi hydromen 9.39 . (9, 3H COOHn also small peaks at 2.25 and 6.85 8. Tlulecular weiţht: Caled: 330.0. Found: 346. A satufactory elemental analysic wa obtained va its derivative. compound 8

Y.N'-Ethylenodisucainimaic Acid (14)

Ethylenediamine ( $30 \mathrm{~g} .0 .50$ mole) and suecinie anhydride $(100 \mathrm{~g}, 1.00$ mole) were used. The product $(125.1 \mathrm{~g} .96 \%)$ was reeryatalized from $95 \%$ ethanol which contained about $2 \%$ of $6 \mathrm{~N}$ 


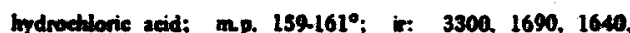
$1550 \mathrm{en}^{-1}$; num (deuterium oxide): (f) 2.68 (2t, 8th. $\mathrm{OCCH}_{2} \mathrm{CH}_{2} \mathrm{COOH}$, 3.36 (a $4 \mathrm{H}, \mathrm{CONHCH}_{2}$ ).

Anel Calod for $\mathrm{C}_{10} \mathrm{H}_{1}, \mathrm{O}_{6} \mathrm{~N}_{2}$ : C. 46.15: $\mathrm{H}, 6.20 ; \mathrm{N}, 10.76$. MT, 260.2 Found: C. 46.06; H. 6.25; N, 10.68; Mw, 270. N,N Ethylene bir(NAStethytauceinamie Acid) (15).

eym-Dimethylenediamine (5 $3.0 .05 \%$ mole) and sueeinis mhydide (11.35 \& 0.114 moie) were wed. The product (17 \&. 99\%) was recryalalized from $95 \%$ ethanol which contained abous 28 of $6 N$ hydrochlorie aeid, m.p. 130-1320; ir: 1740 , 1620, $1510 \mathrm{~cm}^{-1}$; nir (deuterium oxide): (8) 2.68 (s. BH, $\left.\mathrm{OCCH}_{2} \mathrm{Cll}_{2} \mathrm{COOH}\right), 3.04$ (m. 6H, $\mathrm{NCH}_{3}$ ), 3.64(t, 4H, $\left.\mathrm{CONCH}_{2}\right)$

Aned. Caled. for $\mathrm{C}_{12} \mathrm{H}_{20} \mathrm{O}_{6} \mathrm{~V}_{3}$ : $\mathrm{C}$ 49.99: H. 6.99: N. 9.72 MW, 208.3. Found: C, 49.91: H, 7.04: N, 9.87; INN, 288 7.7'Dioxo-1,4-piperaxinedibutyric Acid (16).

Piperazine (21.5 g., 0.25 mole) and succinic anhydride ( 50 R. $0.50 \mathrm{~mole})$ were used. The product $(54.5 \mathrm{~g} .76 \%)$ was recrystal. lized from hot ethanol. m.p. 156.6.158.5०; is: $3000,1720.1600$. $1490 \mathrm{em}^{-1}$ : nmr (deuterium oxide): (8) 269 (2t. $\mathrm{BH}$. $\mathrm{OCCH}_{2} \mathrm{CH}_{2} \mathrm{COOH}$ ), 3.68 (t. $8 \mathrm{H}_{4} \mathrm{CONCH}_{2}$ ).

Anal Caled. for $\mathrm{C}_{13} \mathrm{H}_{18} \mathrm{O}_{6} \mathrm{~N}_{2}: \mathrm{C}_{3} 30.35$ : H. 6.34: $\mathrm{N}, 9.78$ MW, 286.5. Found: C. 30.14: H, 6.41: N, 9.93; MW. 280.

243-Carboxy-N-methylpropioumido)ethyl Hydrogensuccinate (17)

2(Methylaminojethanol (18.i6 z. 0.25 mole) and succinie anhydride ( 50 g. 0.50 mole) were ueed. The product $(68.3 \mathrm{~g}$. 997) was a viscones liquid: ir: $1740,1620,1310 \mathrm{~cm}^{-1}: \mathrm{nmr}$ (6) 2.69 (2t, 8H, OCCH $\mathrm{CH}_{2} \mathrm{COOH}$ ), 3.05 (2d. 3H. . NCH 3 , 3.68(t, 2H, $\left.\mathrm{CONCH}_{2}\right), 4.28(\mathrm{t}, 2 \mathrm{H}, \mathrm{COOCH} 2), 9.90(\mathrm{~s}, 1 \mathrm{H}, \mathrm{COOH}, 10.57$ (a) ith, COOH).

And Caled for $\mathrm{C}_{1}, \mathrm{H}_{1}, \mathrm{O}_{7} \mathrm{~N}$ : Co 48.00: H. 6.23: N, 5.09: MW, 277.3. Found: C. 47.85; H, 6.36; N, 5.21; MW, 275 .

Thiodiethylene bir(Hydrogen succinate) (18).

Thiodiethylene odyeol (30.53 $\mathrm{z}, 0.25$ mole) and suecinie anhydride $(50 \mathrm{~g}, 0.50$ mole) were used. The product $(30.7 \mathrm{~g}$. 38\%) was reeryetallized frosa ethanol, m.p. dec $>120^{\circ}$ : ir: 1720 . $1160 \mathrm{~cm}^{-1}$; nnr: (6) $2.30\left(\mathrm{~s}, 8 \mathrm{H}\right.$. OCCll $\left.\mathrm{CH}_{2} \mathrm{COOH}\right) .286(\mathrm{t}$. 4H. $\mathrm{CH}_{2} \mathrm{SCH}_{2}$ ), 4.30 (t. $4 \mathrm{H}, \mathrm{COOCH}$ ), 7.85 (a, 2H, coOHn. Molecular weight: Caled: 3223. Found: 326.

Oxybir(ethyleneoxyethylene) bix (Hydrogenglutarate) (19).

Tetraethylene giycol (194 c. 1.00 mole) and dutaric anhydride $(223.2 \mathrm{z} .2 .00$ moke) were uner. The product $(400 \mathrm{~g} .95 \%)$ was - recous liquid: if: $17+10,1150 \mathrm{~cm}^{-1}$ : $\mathrm{nmr}$ (o) 203 (m 4t. $\mathrm{CH}_{2} \mathrm{CH}_{3} \mathrm{CH}_{2}$ ), 2.88 (h, 8H. $\mathrm{CH}_{2} \mathrm{CH}_{2} \mathrm{CH}_{2}$ ), 3.66 (s and t, 12H. $\mathrm{CH}_{2} \mathrm{OCH}_{2}$ ), 4.28 (t. $\left.4 \mathrm{H}, \mathrm{COOCH}\right)_{2}, 10.32$ (4. 2H, $\mathrm{COOH}$.

Anech Caled. for $\mathrm{C}_{18} \mathrm{H}_{30} \mathrm{O}_{11}$ : C..31.18: H. 7.16: $\mathrm{MW}, 422.4$ Pound: C, 30.98: 4, 7.12: VW, 48

Macroorelie Compounds.

1,49.12-Tetroxasy elohexadeense-5,8.13,16-letrone (1).

Suceingl thloride (15.0 g., 0.097 mole) and ethylene diycol (6.0 go 0.097 mole) were used. The viscous product $(19.0 \mathrm{~g}$. $60 \%$ ). wa purified by alumina thromatoeraphy and partially eystallized upon standing: ir: $17.40 \mathrm{~cm}^{-1}$ : amr: $(\delta) 270(\mathrm{~s}$ 8H, $\mathrm{COCH}_{2} \mathrm{CH}_{2} \mathrm{CO}$ ), 4.34 (2, 8H. $\left.\mathrm{COOCH}_{2}\right)$.

Anel Caled for $\mathrm{C}_{12} \mathrm{H}_{16} \mathrm{O}_{8}: \mathrm{C}_{50.00} ; \mathrm{H}_{4}$ 5.60; 31 , 288.3. Found: C. 49.82: H. 5.62: MW, 286 .

1,4.7,10,15,18-Hexzoxacyelodoconane-11.14,19.22.tetrone (2)

Ethylenebiel oxyethylese bix(hydropenenccinute) diehloride from $11(15.48 \mathrm{~g}, 0.04$ mole) and ethylene dyeal $(2.73 \mathrm{~g} .0 .04$ mola) were used. The vicosus produret $(0.20$ on $0.5 \%)$ wan purified by alumina chromatography: ir: $17+0 \mathrm{~cm}^{-1}$ : nmor: (6) 2.67 (t. 8H. $\mathrm{COCH}_{2} \mathrm{CH}_{2} \mathrm{CO}$ ), 3.67 (s. 4H, $\mathrm{CH}_{3} \mathrm{OCH}_{2}$, 3.73 (t) 4H. $\mathrm{COOCH}_{2} \mathrm{CH}_{2} \mathrm{O}$ ) +26 (t. $4 \mathrm{H}, \mathrm{COOCH}_{2}$ ), 4.33 (s. $4 \mathrm{H}$ $\mathrm{COOCH}_{2} \mathrm{CH}_{2} \mathrm{OOC}$ ).

Anal. Caled. for $\mathrm{C}_{16} \mathrm{H}_{2} \mathrm{O}_{10}$ : C. 51.05; H, 6.44; $\mathrm{MW}, 376.4$ Found: C, 50.72: H. 6.60: WW. 352

1,4Dioxz-9,12-dinzary clohexadecane-5,8,13.16-1etrone (3).

Ethylene bis(hydrogenuccinate) dichioride from $9(13.69 \mathrm{~g}$. 0.05 moie) and excesse ethylene diamine $(6.0 \mathrm{z}, 0.1 \mathrm{~mole})$ were uxed. The product $(6.0 \mathrm{~g} .46 \%)$ was extracted and reerystallized from chloroform. m. p. 190.192: ir: 3300, 3120,1725. 1640. $1560 \mathrm{~cm}^{-1}$ : ntmr (deuterium oxide): (o) $2.64(\mathrm{~m} .8 \mathrm{H}$. $\mathrm{COCH}_{2} \mathrm{CH}_{2} \mathrm{CO}$ ). 3.38 (4. $4 \mathrm{H}, \mathrm{NHCH}_{2} \mathrm{Cl}_{2} \mathrm{NH}$ ), 4.39 (4. $4 \mathrm{H}$ $\mathrm{COOCH}_{3} \mathrm{CH}_{2} \mathrm{OOC}$ ).

Anal. C.aled. for $\mathrm{C}_{12} \mathrm{H}_{18} \mathrm{~N}_{2} \mathrm{O}_{6}: \mathrm{C}_{0}, 30.38 ; \mathrm{H}, 6.30 ; \mathrm{N} .9 .78$; MW, 286.3. Found: C. 50.10; H. 6.19; N, 9.65; $11 \mathrm{~W}, 280$. 1,4,7.Trioxa-12.15-diazacy clononadecano-8.11.16,19-tettone (4).

Oxydiethylene bia(hydrogersuccinate) dichloride from $10(34.3$ c. 0.1 mole) and exces ethylene diamine (12.6 g.o 0.21 mole) were used. The product $(2.69 \mathrm{g.} .8 \%)$ was extracted and recrystal lized from chloroform, m.p. 167.168\%; ir: 3300, 3100. 1740. 1660 and $1355 \mathrm{em}^{-1}$; $\mathrm{nm}$ (deuterium oxide): (6) $263 \mathrm{~lm}$ 8H, $\mathrm{COOCH}_{2} \mathrm{CH}_{2} \mathrm{CONH}$, 3.33 (s, 4H. $\left.\mathrm{NHCH}_{2} \mathrm{CH}_{2} \mathrm{NH}\right), 3.80$ (t. 4. $\left.\mathrm{CH}_{2} \mathrm{OCH}_{3}\right)+4.28\left(\mathrm{t}, 4 \mathrm{H}, \mathrm{COOCH}_{2}\right)$.

Amal Calcet foe $\mathrm{C}_{1} \mathrm{H}_{22} \mathrm{~N}_{2} \mathrm{O}_{7} \cdot 3 \mathrm{H}_{2} \mathrm{O}$ : N. 7.29; $\mathrm{MW}, 384$ Found: N, 7.22: MW, 350.

1.4,7,10-Tetraxa-15,18-dianeyelodocosene-11,14,19,22-tetrone (b).

Ethylenebid(oxyethylene) bis(hydrogensucerinate) dichloride from 11 ( $38.2 \mathrm{~g}-0.10$ mole) and excew othylenediamine (12.6 g. 0.21 mole) were ueat. The product $(3.74 \mathrm{~h} .10 \%)$ was extracted and recrystallized from chloroform, m.p. $159-161^{\circ}$; ir: 3300 3100. 1725, $1640.1550 \mathrm{~cm}^{-1}$; nme (6) $2.63(\mathrm{~m} .8 \mathrm{H}$ $\mathrm{COCH}_{2} \mathrm{CH}_{2} \mathrm{CO}$ ), 3.44 (m. 4H, NHCl $\left.\mathrm{CH}_{2} \mathrm{NH}\right), 3.70$ (t. $8 \mathrm{H}$. $\left.\mathrm{CH}_{2} \mathrm{OCH}_{2}\right), 4.30(\mathrm{~L}+\mathrm{H}, \mathrm{COOCH}), 6.62(\mathrm{~s}, 2 \mathrm{H} . \mathrm{NH})$.

Anel Calcd. for $\mathrm{C}_{16} \mathrm{H}_{25} \mathrm{~V}_{2} \mathrm{O}_{3}$ : C, 31.33; $\mathrm{H}, 7.00: \mathrm{N}, 7.48$ : MW, 374,4 Found: C, 31.08; H, 7.16; N, 7.28: MW, 399 .

4-Benoyl-1,7,12,15-tetraoxa-4-azacy elonomadecane-8,11,16,19. tetrone (6).

Ethylene bidhydrogensuecimate) dichloride from 9 (29.9 g. 0.1 mole) and 2.2 thenxytiminontiethanot (14.1 x. 0.07 mole) were used. The product $(1.5 \mathrm{~g}, 5 \%)$ was purified by alumina chromalograpity: is: $1740 \mathrm{~cm}^{-1}$ : nmr: (6) 2.63 (d. $8 \mathrm{H}$. $\left.\mathrm{COCH}_{2} \mathrm{CI}_{2} \mathrm{CO}\right), 2.78\left(\mathrm{t}, 4 \mathrm{H}, \mathrm{NCH}_{2} \mathrm{CH}_{2} \mathrm{O}\right), 3.68\left(\mathrm{~s}, 2 \mathrm{H}, \mathrm{PhCH}_{3} \mathrm{M}\right.$, $413\left(\mathrm{t}, 4 \mathrm{H}, \mathrm{NCH}_{2} \mathrm{CH}_{2} \mathrm{O}\right), 4.30\left(\mathrm{~d}, 4 \mathrm{H}, \mathrm{COOCH}_{2} \mathrm{CH}_{2} \mathrm{COO}\right), 7.26$ (s, 5 h, aromatie).

And Ciled for $\mathrm{C}_{2}, \mathrm{H}_{27} \mathrm{NO}_{3}-2 \mathrm{H}_{2} \mathrm{O}$ : N, 306: M4, 457. Found: N, 3.20: MW, 454

1,4,7,12,15,18-Hexaoxacyciodoeove-9,20-diene-8,11,19,22-tetrone (7).

Oxydiethylene bis(hydrogenmaleste) dichloride from 1217.5 o, 0.02 mole) and dietinylent dyeol (2.34 g., 0.02 mole) were ued. The product $(1.32 \mathrm{~g}, 16 \%)$ was recrystallized from $100 \%$ ethanol. an $127.3 .128^{\circ}$; is: $1720 \mathrm{em}^{-1}$ : nmr: (s) 3.76 (t. 8H, $\mathrm{CH}_{2} \mathrm{OCH}$ ), 4.45 (t, BH, $\mathrm{COOCH}$ ), 6.95 (a, 4H, vinyl $\left.\mathrm{H}\right)$

Anal Caled. for $\mathrm{C}_{16} \mathrm{H}_{20} \mathrm{O}_{10}: \mathrm{C}_{4}, 31.64: \mathrm{H}, 5.37$ : Yw, 372 Found: C. 5L.45; H, 5.50: MW, 389 . 


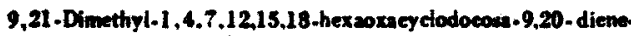
8, 11, 19, 22-tetrone (8).

Oxydlethylens bidhydrogencitraconate) dichloride from 13 (21 2., 0.06 mole) and diethylene glycol ( $5.0 \mathrm{~g}, 0.05$ mole) were uned. The product $(0.11 \mathrm{m.} 1 \%)$ wes purified by alumina elrematoguphy: ir: $1720 \mathrm{em}^{-1}$; nme: (o) 205 (s. 6H, $\mathrm{CH}_{3}$ ). $3.70\left(\mathrm{~m}, \mathrm{aH}, \mathrm{CH}_{2} \mathrm{OCH}_{2}\right)+32\left(\mathrm{~m} .81 \mathrm{~L}, \mathrm{COOCH}_{2}\right), 5.90(\mathrm{~s}, 2 \mathrm{H}$ vert Hh aleo small peaks at $2.2 \%$ and 6.838 .

Anal Caled. for $\mathrm{C}_{18} \mathrm{Il}_{24} \mathrm{O}_{10}: \mathrm{C}_{4}, 53.99 ; \mathrm{H}, 6.04 ; \mathrm{MW}, 400$. Pound: C, 53.80; H, 6.06; MW, 388.

Acknowledgements.

This work was partially supported by National Science Poundation Grant Clte 76-10091 and National Institute of Ifealth Grant GM-18811-04. A researm grant to S. F. N. from the Amociated Students of Brigham Young University is also acknow. lediged.

\section{REFERENCES AND NOTES}

(1) Presented at the Fall Semiannual Veeting of the Utah Acodemy of Science, October 1976.

(2) To whom inquiries should be sent.

(3) J. J. Christersen, D. J. Eatough, and R. II. Izatt. Cham. Reve, 74, 351 (1974).

(4) R. IL Ixatt, D. J. Eatoumh, and J. J. Christenwen, Struc Bonding (Bestin). 16. 161 (1973).

(5) R. M. Inatt, R. E. Terry, B. L. Haymore. Lo D. Hansen N, K. Dalley, A. G. Awondet, and J. J. Christensen, J. Am, Chem.
Soe, 92, 7620 (1976).

(6) R. M. laati. R. E. Terry, D. P. Netson, Y. Chan, D. J. Batough. J. S. Beadaluaw, L. D. Hanuen and J. J. Christeneen. ibid. 98. 7626 (1976).

(T) Yu. A. Orchinnikov. V. T. Ivanov, and A. M. Shkrob. "Membrane Active Cumplexones". Eleverier, New York. 1974.

(8) S. E. Dewes and P. C. Colemen f. Chem, Socm Perkia Trane 1.2148 (1972).

(9) S. E. Dewes and B. C. Riphagen, ibid., 323 (1974).

(10) S. E. Dewey and B. G. Riphagen, ibid. 1908 (1974):

(II) J. S. Brodshaw, L. D. Hansen. S. F. Vielsen. It. D. Thompeon R. A. Reeder, R. II. laatt, and J. J. Cliristensen, 1. Chem Soco, Chem Commun. 87 $\$(1975)$.

(12) J. S. Bradsinaw. C. T. Bistiop. S. F. Nielson. R. E. Asay, D. R. K. Vtasihdas E. D. Flanders. L D. Hansen, R. I1. Izatt, and J. J. Christensen, J. Chem. Soc.. Perkin Truns. I. in press.

(13) W. R. DePiere. Sr.. and H. L. Nilder, L. S. Patent 3.639.376. Feb. 1, 1972; Chem thatr. 76. 1+154p (19-12). (14) A. L. Suvarov and T. A. Perlyaeva. Trans. Inst. Khim. Ahed. Nauk SSSR, Urod Titial. H (1971).

(15) See for example. T. Hino and T. Sato, Chem. Pharm. Bulk. 22. 2866 (1974).

(16) R. Buyle, Hetw. Chim. tcta. 49.1\$25 (1966)

(17) H. Natsuda and $\mathrm{S}$. Waizumi. Japanese Patent ..036.,31.

(18) R. A. Sprog .I. Chem. Soc. (B), 1128 (1968).

(19) Y. Miron, B. R. MeBarvey and II. Moraivety, Hoero. molecules, 2. 154 (1969).

(20) C. A. Buehler and D. E. Pearson. "Survey of Organic Synthesia," Ailey Interseience, New York, 1970. p. 860.

(21) C. J. Pedewen. J. Am. Chem. Soc. 89, 701: (1967). 
Preparation of Macrocyclic Ether-Esters, Thioether-Esters, and EtherThiolesters ${ }^{2}$

By Serald S. Bradehaw, Clark T. Bishop, Steven F. Nialsen, R. Elliote Asay, David R. K. Masihdas, E. Deen Flandors, Lee D. Hansen, Reed M. Izatz, and James J. Christenzen, Dopartment of Chemistry and Chemical Engineering and Center for Thermochornical Studiea, Brigham Young University. Prova, Utah 84602

A series of macrocyclic ether-osters. thioethor-osters. and ether-thiolesters $[(1)-(10)]$ have been prepared by treating various oligo-ethytene glveols and sulphur-containing oligo-ethylene glycols with malonyl. succiny. and glutaryi chiorides.

We have previously reported the synthesis $2-b$ and cationcomplexing properties " of several axathinpentadecanes and thio-crown compounds. Several of the thio (crown-5) compounds were shown to form mare stable (as mensured by $\log K$ ) complestes in aqueous solution with $\mathrm{Ag}^{+}$and $\mathrm{Hg}^{2+}$ than with $\mathrm{\Pi}^{+}$and $\mathrm{Pb}^{2+}$. Also. metal-lignand complexes of $1: 2$ stoicheiometry were formd for the reaction of $\mathrm{Ag}^{*}$ and $\mathrm{Hg}^{\mathrm{st}}$ with several of the thio-crovsn ligands." Wie present bere the synthesis of compounds (1)-(10), containing ether, ester, thio-

1 Preliminary communieation. J. S. Bradlshaw. L. D. Harsen. S. F. Nietsen, M. D. Thompson. R. A. Reeder, R. 2t. Inatt, and J. J. Cluristersen, J.C.S. Cisul. Comm., 1075, 87t

J. J. J. S. Beadshaw, j. Y. Hui, B. L. Fiaymore. J. J. Ciristensea,

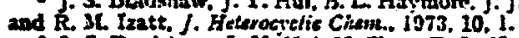

a. J. Eradshaw. J. Y. Ifut. Y. Clian, B. L. Haymore. R. Mr. Intte and I. J. Christensen, J. Hitiarogetlic Chem., 1974, 11 , 45. C.J. S. Braduhaw, B. L. Haymire, R. It Izatt, and J. J. Chrieteneen, J. Ong. Chesu, 1975, 40. 1310 . ether, and thiolester groups. A calorimetric investigation of the ration-complexing properties of these compounds has been started.

The formation of macrocyclic esters has been reparted previously. Drewes and his co-workers have studied a number of macrocyclic di-and tetra-esters from phthalic and maleic acid systems. They treated the dipotassium salts of phthaile and maleic acid with a series of alkyl and aikynyl dibromides to make 10-34-membercd ring compounds, ${ }^{t \rightarrow} \rightarrow$ Similar compounds have been reported 'J. S. Bradshaw, R. A. Reeder, M. D. Tiuorapmon, E. D. Flaniers, R. L. Carruth, R. Ji. Izatt, and J. J. Ciristensen, $J$ Org: Cnema. 1076. 41. 134.

S. At. Izatt. R. E. Terry, L. D. Hansen. A. G. Avoadet J. S. Bndshaw, X. K. Dalley, T. E. Jensen, B. I. Haymore, and J. Christensen. in preparation.

S. E Drowes and P.C. Coleman. J.C.S. Porkin I. 1972, 2143.

S. E. Drowes and B. G. Riphargen, J.C.S. Prrkin R. 1074. 323 S. E. Drowes and B. G. Riphages, J.C.S. Pathin I, 1974 
<smiles>O=C1CC(=O)OCCOCCOCCO1</smiles>

(1)<smiles>O=C1CC(=O)OCCOCCOCCOCCO1</smiles>

(2)<smiles>O=C1CC(=O)OCCOCCOCCOCCOCCO1</smiles>

(3)<smiles>O=C1CC(=O)SCCOCCOCCOCCS1</smiles>

(4)<smiles>O=C1CCOCCSCCSCCOCCOC(=O)C1</smiles>

(5)<smiles>O=C1CCC(=O)OCCOCCOCCOCCO1</smiles>

(6)<smiles>O=C1CCC(=O)OCCOCCOCCOCCOCCO1</smiles>

(7)<smiles>O=C1CCOCCOCCOCCOCCSC(=O)CC1</smiles>

(8)<smiles>CCOCCSCCCSCCOCCOC(=O)CCC(=O)OCC</smiles>

(9)<smiles>O=C1CCCC(=O)OCCOCCOCCOCCOCCO1</smiles>

(10)<smiles>O=C(Cl)CC(=O)Cl</smiles>

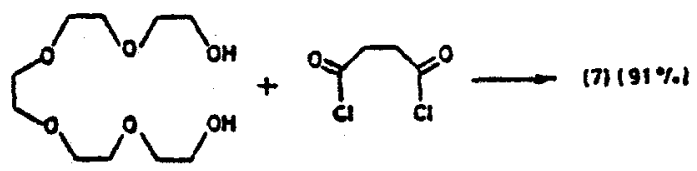

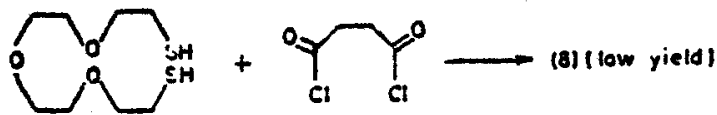

by other workers. to Howrever, macrocyclic esters containing the oxyethylene unit like those described here have not been reported.

The macrocyelic esters and thiolesters were prepared by treating the appropriate glycol or dithiol with malongl, succingl, or glutaryl citloride. The oligo-

ethylene giycols are available commercially, and their thio-analogues can be prepared in the laboratory. The reaction was run at high dilution by adding the starting materiais from separate dropping funnels to benzene at 10 Soe refecence 7 for 2 seview of othar macrocyclic ester syatheser. 
$50{ }^{\circ} \mathrm{C}$. Yields were generally in the range $27-01 \%$. The thiolosters (4) and (8) appeared to be unstable.

The structures proposed for the macrocycles are consistent with i.r. and n.m.r. spectra, clemental analyses, and molecular weights. The esters all exhibit is. bands at I 730-1740 $\mathrm{cm}^{-1}$ and the thiolesters (4) and (8) bands at $1090 \mathrm{~cm}^{-1}$. All the malonate esters [(1)-(3) and (5)] exelibit n.m.r. peaks at $\delta 3.42 \pm 0.01$ $\left(\mathrm{O}_{2} \mathrm{C}_{-} \mathrm{CH}_{3} \mathrm{CO}_{3}\right)^{\prime \prime}$ The corresponding peak for compoumd (4) is shifted to \& 3.75. by approximately the same amount as observed in comparing the acctate methyl penk for Sethyl thioacetate and ethyt acetatc. ${ }^{11}$ The succinates $[(\theta),(7)$, and (9)] exhibit n.m.r. peats at $82.70 \pm 0.02\left(\mathrm{O}_{2} \mathrm{C} \cdot\left[\mathrm{CH}_{2}\right]_{2} \cdot \mathrm{CO}\right)_{3}{ }^{11}$ Corresponding peaks for the thiolester (S) are shifted by much the same amount as mentioned above for compound (t). Corrpound (10) exhibits n.m.r. peaks similar to those of diethyl glatarate." The $\mathrm{CO} \cdot \mathrm{O} \cdot \mathrm{CH}$, groups of the esters exhibit n.m.r. peaks with similar chemical shifts to those at $\$ 4.22$ for diethyl malonate 't $[(1)-(3)$ and (5)]; at 84.13 for diethyl suecinate $1 \mathrm{f(}(0)$, (7), and (0)]; and at 84.15 for diethyl glutarate 11 [(10)\}. The S.CH, groups of compounds (5) and (9) exinibit peaiks at $\$ 2.8 \pm 0.1$ as previously reported.23 The $\mathrm{S} \cdot \mathrm{CH}_{2}$ signals for compounds (4) and (8) were at $\delta 3.1 \div 0.1$. The ether $0 \mathrm{CH}_{2}$ sroups all exhibited peaks at $83.7 \pm 0.1$. Mrethylene groups $\beta$ to sulphur or to an ester group gave peales at lower field, as previousily reported.1.2

The thiolesters ( $t)$ and (B) appear to be unstable. Repeated chromatography on alumina always gave a product which exhibited small i.r. bands at $2530 \mathrm{~cm}^{-1}$ and an n.m. triplat at 81.6 (SH). We were able to porify compound (t) vell enough for a satisfactory combustion analysis.

\section{EXPERETUENTAL}

I.r. spectra were obtained with a Hilger and Vatts H1200 Infragraph. N.m.r. spectra were obtained with Varian ACO-A and Exis9o spectrometers. Elemental andyses and molecular woight determinations were performed by MIIIV Laboratories, Carden City, Michigan, and by Galbraith Iaboratories. Inc. Kinoxville, Tenuesses.

Senting Mratovials, - Xiost of the sturting glycois and acid chlorides were used as parchised: ethanedithiol (Aldrich). 2-(2-hiurouthoxy)ethanol (Barish), triethylene glycol (B.loor). tetractinglen glycol (Aldrich), pentacthylene dyeel (Columbin), malonyt chloride (Aldrich), suceinyt ehloride (Aldrich), anul giutaryl chloride (Aldrich). 3,6,9 Trineunatecene-1.11-dithioh, $2560 \mathrm{~m}^{-1}$ (SH). was propened from tetracthylcne giveoi by the thiourea method 3.12-Dien-6,9-lithiaterralecone-1,14-diol was prepared (76\%) by treating cthanedithiol with 2-(2-chlurvethoxy)ethanol and sodium ethoxide in ethanol; ${ }^{2}$ the product exchibited $8.95\left(8 \mathrm{H}, \mathrm{m}, \mathrm{S}-\mathrm{CH}_{2}\right)$ and $3.20\left(14 \mathrm{H}, \mathrm{m}, \mathrm{O}-\mathrm{CH}_{2}\right.$ and $O F$.

Genmal Procedure for Symthesis.-The glycol and acid chloride, each dissolved in benzene (200 nil) were slowly -added simultaneousiy to stirzed benzene $(000 \mathrm{ml})$ at $50^{\circ} \mathrm{C}$. A nitrogen atmospliere was maintriued where solphue

It Ses Sedtier n.m.r. spectro nos 11 t49 (liethyl malonate) 10 291 (othyl ecetite). 21 1s2 (S-ethyt thioncotate). 193 (diotityt acciante), and $\$ 258$ (dietingl glutarate). componnds were used. The nixture vas stirred at 5060 "C for at least 2 days. Longer reaction periods gave higher yields. The atmosphere over the misture was found to be acidie. After the renction was stomped, benzerne was removed under vacuam. The crude prodinct was then purified by recrystallization or by chroniatography on alumina with hexino containing increasing amounts of chloroform as cluent. Specific details are given for each compound.

$1,4,7,10-T$ atrateracyelotridecane-11,13-dions (1). Triethyleue glycol $(10 \mathrm{~g} .0 .067 \mathrm{~mol})$ aud malonyi chloride (9.38 g, $0.067 \mathrm{~mol}$ ) were used. Thu product ( $4.8 \mathrm{~g} .34 \%$ ) had m.p. $51.3-62.5{ }^{\circ} \mathrm{C}$ (from chloroform-trexune): $1710 \mathrm{~cm}^{-1}$ : \& 3.00 (2 H, s, COCH.CO), 3.64 (4 H, s,

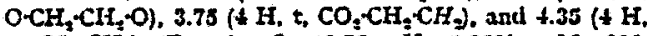
$t . \mathrm{CO}_{2} \mathrm{CH}_{2}$ ) (Found: C. $10.75 ;$ If, 6.65\%; $\mathrm{M}, \mathbf{3 2}$. C. $\mathrm{H}, 0$, requires C. 49.55; H, 6.45\%; M, 218. $\%$.

$1,4,7,10,13-P_{\text {entaaracyclohezadecana-14, 16-dione }}$

Tetrethylene glyeol (15.0 g, $0.077 \mathrm{~mol})$ and mainnyl chloride $(10.2 \mathrm{~g}, 0.077 \mathrm{nol})$ were used. The prociuct $(5.5 \mathrm{~g}$ $27 \%$ ) had m.p. $67-68{ }^{\circ} \mathrm{C}$ (from chloroform-hexane):

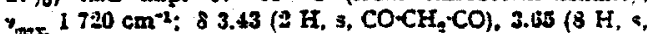
$\left.\mathrm{O} \cdot \mathrm{CH}_{2}+\mathrm{CH}_{2} \cdot \mathrm{O}\right), 3.73\left(4 \mathrm{H}, t, \mathrm{CO}_{2} \mathrm{CH}_{2} \cdot \mathrm{Clt}_{4}\right), 4.34$ (4 H, $\mathrm{t}$, $\mathrm{CO}_{2}+\mathrm{CH}_{2}$ ) (Found: $\mathrm{C}, 50.3 ; \mathrm{H}, 6.35 \% ; M, 247 . \mathrm{C}_{11} \mathrm{H}_{10} \mathrm{O}_{8}$ requires $C, 30.4 ; H, 6.9 \% ; M, 262.26)$. The same product was isolated in $1-2 \%$ yich by nutuxing malonic acid and tetracthytene glycol in benzene with a trace of tolueno-psulphonic acid.

1,4,7,10,13,16-Hexwoxacycionousdecano-17,19-dious (3). Pentretbriene giycol (15 g, $0.063 \mathrm{~mol})$ and nulonyl chloride $(8.88 \mathrm{~g}, 0.063 \mathrm{~mol})$ vere used. The protiuct $(7.5 \mathrm{~g}, 38 \%)$ had m.p. 37-58 ${ }^{\circ} \mathrm{C}$ (from chloroform-hexane): $1720 \mathrm{~cm}^{-3} ; 3.43\left(2 \mathrm{H}, \mathrm{s}, \mathrm{CO}-\mathrm{CH}_{2} \mathrm{CO}\right), 2.67$ (12 $\mathrm{H}_{1} \mathrm{~s}$ $\left.\mathrm{O} \cdot \mathrm{CH}_{2}+\mathrm{CH}_{2} \mathrm{O}\right), 3.77\left(4 \mathrm{H}, \mathrm{t}, \mathrm{CO}_{2}-\mathrm{CH}_{3}-\mathrm{CH}_{2}\right)$, and $4.33(4 \mathrm{H}$, $t, \mathrm{CO}_{2} \mathrm{CH}$ ) (Found: C. 50.75; H. $7.13 \%$; 32.931 . $\mathrm{C}_{33} \mathrm{H}_{32} \mathrm{O}$ requires C. 51.0; H, 7.25\%; 34, 306.31).

1,\$,7-Trioxa-10,14-dithiacyelohesadecane-11,13-dione (4). $3,6,9$-Trioxandecanc-1,11-dithiol $(17 \mathrm{~g}, 0.076 \mathrm{~mol})$ and malonyl chloride (11.5 g, $0.070 \mathrm{~mol})$ were used. The product was purified on an alumina column (yield $<1$ g): it decomposed when hezted, as shown by the appearance of an i.r. band at $2550 \mathrm{~cm}^{-3}$. Conspounul (4) exhibited v $1690 \mathrm{~cm}^{-2}$; 83.15 (4 H, t, CO.S-CH.), 3.63 (8 $\mathrm{H}^{\mathrm{m}} \mathrm{s}$. $\left.0-\mathrm{CH}_{2}+\mathrm{CH}_{2}-\mathrm{O}\right)$, 3.68 (4 H, t, CO.S.CHI $-\mathrm{CH}_{3}$ ), and 3.75 (2 H, s, COCH, CO) (Eound: C, 44.75; H, 6.45; $S$, $21.55 \%$ : HF, 279 . $\mathrm{C}_{18} \mathrm{H}_{10} \mathrm{O}_{3} \mathrm{~S}_{2}$ requites $\mathrm{C}$, 4.0; $\mathrm{H}, 6.15$; S, $21.8 \%$ : if, 204.39).

1,4,13,16-Tetraoza-7, 10-diwhiacyclononedecane-17, 19-dions (5). 3.12-Diox-6,9-dithiatetradecane-1,14-diol (27 $\mathrm{g}, 0.10$ mol) and malonyl chloride ( $14.1 \mathrm{~g} .0 .10 \mathrm{~mol}$ ) wert wael. The viscous prodzet $(28.1 \mathrm{~g}, 85 \%)$, was purified by chro matography on alumins: $v_{\text {the }} 1740 \mathrm{~cm}^{-1}$; 8.78 (8 H. m, $\mathrm{S}-\mathrm{CH}_{2}$ ), 3.47 (2 H, s, CO.CH, $\mathrm{CO}, 3.72$ (8 H, m, O.CH, and 4.35 (4 H, t, CO, $\mathrm{CH}$ ) (Found: $C, 45.95$; $\mathrm{H}, 6.05$ : $\mathrm{S}$, $13.75 \% ; M, 350$. $C_{2} \mathrm{H}_{\mathrm{z}} \mathrm{O}, \mathrm{S}_{2}$, requires $\mathrm{C}, 16.15 ; \mathrm{H}, 6.55$; S, $18.35 \%$; $M$. 338.45$)$.

1,4,7,10,13-Pentasoxacycloheptadecane-14,17-dione (6). Tetriethylene giycol $(15 \mathrm{~g}, 9.077 \mathrm{~mol})$ and succinyl chloride (11. $\$$ g. $0.077 \mathrm{~mol}$ ) were used. The light yellow viscous oil was purified on alumina; yield $0.30(20 \%$ based on the imfotint of product purificd): $1735 \mathrm{~cm}^{-1}$; $82.72(+\mathrm{H}$, s. $\left.\mathrm{COCH},-\mathrm{CH}_{2}+\mathrm{CO}\right), 3.68\left(8 \mathrm{IH}, \mathrm{s} . \mathrm{O} \cdot \mathrm{CII}_{2} \cdot \mathrm{CH}_{2} \cdot \mathrm{O}\right) .3 .72(4 \mathrm{H}$, $t, \mathrm{CO}_{2} \mathrm{CH}_{3} \mathrm{CH}_{2}$ ), and 4.32 ( $\mathrm{t} \mathrm{H}, \mathrm{t}, \mathrm{CO}_{2}+\mathrm{CH}_{-}$) (Found: $\mathrm{C}$,

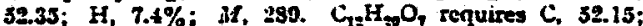
H. 7.3\%: $\mathrm{H}, 276.03)$. 
1,4,7,10,13,10-Hexaoxacycloatcosanso-17,20-dione Pentuethylene glyeol ( $19 \mathrm{~g}, 0.08 \mathrm{~mol}$ ) and succinyl chlorido (12.4 $\mathrm{g}, 0.08 \mathrm{~mol}$ ) were usch. The mixture was stirsed at $50{ }^{\circ} \mathrm{C}$ lor 6 dnys. The crude product was filtered through a small amount of alumina, and the alumion was washed with chlorolorm (25 all). The product ( $25 \mathrm{~g} .90 \%$ ) was a visoous ail; : $17+0 \mathrm{~cm}^{-1} ; 82.68$ ( $\$ \mathrm{H}_{3}, \mathrm{~s}, \mathrm{CO}-\mathrm{CH}_{2} \cdot \mathrm{CH}_{2} \cdot \mathrm{CO}$ ), $3.68\left(16 \mathrm{H}, \mathrm{s}_{1}\right.$, ther $\left.\mathrm{O}-\mathrm{CF}_{2}\right)$, and $4.23\left(\mathrm{H}, \mathrm{t}, \mathrm{CO}_{2}-\mathrm{CH}_{2}\right)$ (Found: C, 32.4; H, 7.45\%; M. 359. $\mathrm{C}_{23} \mathrm{~K}_{21} \mathrm{O}_{3}$ requires C. 32.5; H, 7.35; $3,320.15$ ).

1,4,7-T riara-10,13-dithiacycloheptadeconu-11,14-dione (3) $3,6,9$-Trioxa undecane-1,11-dithiol $(18.1 \cdot \mathrm{g}, 0.08 \mathrm{~mol}$ ) and suecinyl chloride $(124 \mathrm{~g}, 0.08 \mathrm{~mol})$ were used. The product was dissolved in chloroform and repeatedly extracted with water. The final product (ca. $5 \%$ ) was a light yellow viscous oil: $y=1690 \mathrm{~cm}^{-1}$; $82.8 \overline{5}$ (4 H, s, $\left.\mathrm{CO} \cdot \mathrm{CH}_{2} \cdot \mathrm{CH}_{2}+\mathrm{CO}\right), 3.10\left( \pm \mathrm{H}, \mathrm{t}, \mathrm{S} \cdot \mathrm{CH}_{2}\right)$, and $3.62(12 \mathrm{H}, \mathrm{m}$, $\mathrm{O}-\mathrm{CH}_{2}$. Good elemental analytical results were not obtained.

14,13,16-Tetraoxa-7, 10-dithiacycloeicosane-17, 20-dion (9). 3.12-Diosa-6,9-dithiztetradecane-1,14teliol ( $97 \mathrm{~g}, 0.1 \mathrm{~mol}$ ) and saceingl chloride $(17.1 \mathrm{~g}, 0.1 \mathrm{~mol})$ were used. The product was cluromatographed on alumina to yield a light yellow viscous oil (2S $\mathrm{gl}$; y $1735 \mathrm{~cm}^{-1}$ : $82.08-2.45$ (12 H, m, COCCI, $\mathrm{CH}_{2} \mathrm{CO}$ and $\left.5-\mathrm{CH}_{2}\right) .3 .72(8 \mathrm{H}, \mathrm{m}$, etlies $\mathrm{O} . \mathrm{CH}_{2}$, and $4.28\left(\mathrm{H}, \mathrm{t}, \mathrm{CO}_{3} \cdot \mathrm{CH}_{2}\right.$ ) (Found: $\mathrm{C}, 47.85 ; \mathrm{H}$, 6.95: S. 18.25. $\mathrm{C}_{24} \mathrm{H}_{33} \mathrm{O}_{2} \mathrm{~S}_{2}$ requirus $\mathrm{C}_{0}$ 47.7; H. 6.0; S. $18.2 \%)$.

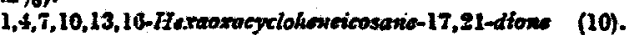
Pentacthylene glycol (10.1 g, $0.08 \mathrm{~mol}$ ) and glutangi chlorible $(13.6 \mathrm{~g}, 0.03 \mathrm{~mol})$ were used. The mixture was stirred at $50{ }^{\circ} \mathrm{C}$ for 6 days. The crude product (2t $\mathrm{g}, 80 \%$ ) was dissolved in chloroform and filtered thurough alunina

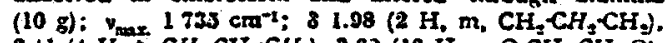

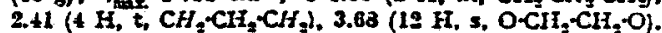

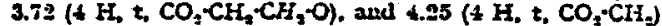
(Found: C. 53.85: H. 7.75. $\mathrm{C}_{23} \mathrm{H}_{22} \mathrm{O}_{2}$ requires $\mathrm{C}_{3}$ 53.5: H, 7.85\%).

We thank G. E. Mans for the preparation of one of the thio-glycols. We also thank the associated student government of B.Y.U. for student grants (to C. T. B., S. F. N., and E. D. E.).

[CHa7s Received, 21st Juser, 1976] 
Synthesis of Two Nowel Cyclic Polyether-Ester Compounds and Some Comparisons of Their Reactions with $\mathrm{Na}_{2}^{+}, \mathrm{K}^{+}$, and $\mathrm{Ba}^{2+}$ with Those of 18-Crown-6 and Valinomycin

Sir:

Macrocyclic polyether molecules such as 18-crown-6 (I) may be both compared to and contrasted with valinomycin (II) and other macrocyclic antibiotics in terms of chemical and physical properties and molecular structure. Both types of molecules are selective for certain alkali metal cations ${ }^{\text {t-5 }}$ and exhibit similar ion transport properties across biological membranes. ${ }^{4}$ Valinomycin shows selectivity for $\mathrm{K}^{+}$over $\mathrm{Ba}^{2+}$ in methanol solution, ${ }^{4}$ while by contrast, the opposite trend is true for 18-crown-6, ${ }^{6}$ as illusirated in Table 1 . In terms of molecular structure, the 36-member ring of II must undergo a greater conformational changet upon complexation with $\mathrm{K}^{+}$ than is required of the 18 -member ring of the crown ligand (I). ${ }^{7}$ Within the $\mathrm{K}^{+}$complex of II, the metal ion is surrounded by an octahedron of carbonyl oxygen atoms, whereas the sixcoordination is nearly compressed into a plane of etherate oxygen atoms within the $\mathrm{K}^{+}$complex of $\mathrm{I}^{2}$

We have synthesized two compounds analogous to I (III and IV) having carbonyl groups available for cation complexation as does valinomycin. $\log K, \Delta H$, and $T \Delta S$ values for the reaction in $\mathrm{CH}_{3} \mathrm{OH}$ solvent of III and IV with $\mathrm{Na}^{+}, \mathrm{K}^{+}$, and $\mathrm{Ba}^{2+}$ are given in Table I together with corresponding values, where available, for the reaction of these cations with $1^{6}$ and II."

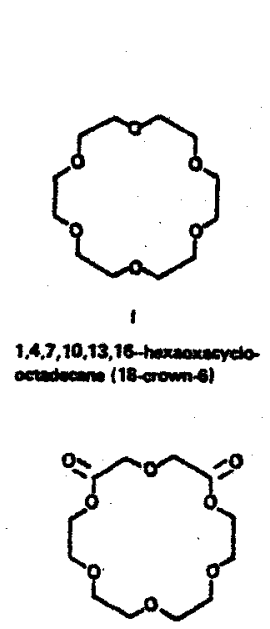

III

\section{$1,6,7,10,13,16$ -}

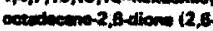
dience-18-anom 61

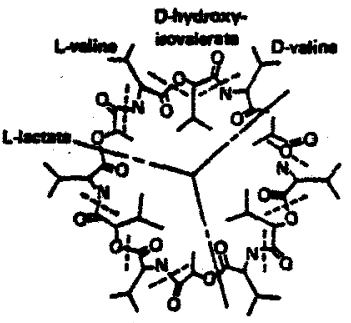

II
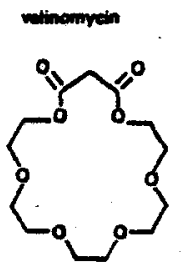

N

$1,4,7,10,13,16$-hareareryelo. nonadecents-17, 19-dione $(2,4$ dione-19 eromes
Significant differences exist between the cation selectivity behavior of either III or IV and that of I as is shown by the log $K$ values in Table $I$. The marked selectivity for $\mathrm{Ba}^{2+}$ over $\mathrm{K}^{+}$ found for $\mathrm{I}$ in either aquecus ${ }^{8}$ or $\mathrm{CH}_{3} \mathrm{OH}^{6}$ solvent and for either isomer of dicyclohexo-18-crown-6 in aqueous solution ${ }^{2.8}$ is absent for both III and IV. In addition, the selectivity of $\mathrm{K}^{+}$ over $\mathrm{Na}^{+}$shown by III and IV is considerably less than that found in the case of $I$. The decreased stabilities of the cation complexes of III and IV are seen to be a result primarily of less exothermic $\Delta H$ values, the $T \Delta S$ values favoring complexation of III and IV relative to I in all cases except that of $\mathrm{Ba}^{2+}-$ IV interaction.
Table $L . L O g K . \Delta H$, and $T \Delta S$ Values for the Reactions at $25^{\circ} \mathrm{C}$ in $\mathrm{CH}_{3} \mathrm{OH}$ Solvent of $\mathrm{Na}^{+}, \mathrm{K}^{+}$, and $\mathrm{Ba}^{2+}$ with Several Macrocyelic Molecules

\begin{tabular}{|c|c|c|c|c|}
\hline Compound & $M^{n+}$ & $\log K^{*}$ & $\begin{array}{c}\Delta H \\
(\mathrm{kcal} / \mathrm{mol})^{a}\end{array}$ & $\begin{array}{c}T \Delta S \\
(\mathrm{kcal} / \mathrm{mol})\end{array}$ \\
\hline$t^{b}$ & $\begin{array}{l}\mathrm{Na}^{+} \\
\mathrm{K}^{+} \\
\mathrm{Ba}^{2+} \\
\mathrm{Na}^{+}\end{array}$ & $\begin{array}{l}4.36 \\
6.05 \\
7.0 \\
0.67\end{array}$ & $\begin{array}{l}-8.4 \\
-13.4 \\
-10.23\end{array}$ & $\begin{array}{l}-2.4 \\
-5.2 \\
0.7\end{array}$ \\
\hline & $\begin{array}{l}\mathrm{K}^{+} \\
\mathrm{Ba}^{2+}\end{array}$ & $\begin{array}{l}4.90 \\
3.34\end{array}$ & -4.54 & 215 \\
\hline III & $\begin{array}{l}\mathrm{Na}^{+} \\
\mathrm{K}^{+} \\
\mathrm{Ba}^{2+}\end{array}$ & $\begin{array}{l}2.5 \neq 0.1 \\
2.79 \pm 0.02 \\
3.1 \pm 0.2\end{array}$ & $\begin{array}{l}-2.27 \neq 0.18 \\
-5.87 \pm 0.01 \\
-0.46 \pm 0.11\end{array}$ & $\begin{array}{l}1.1 \\
-2.06 \\
3.8\end{array}$ \\
\hline IV & $\begin{array}{l}\mathrm{Na}^{+} \\
\mathrm{K}^{+} \\
\mathrm{Ba}^{2+}\end{array}$ & $\begin{array}{l}1.8 \pm 0.18 \\
2.55 \div 0.03 \\
1.41 \neq 0.11\end{array}$ & $\begin{array}{l}-1.1 \pm 0.2 \\
-7.91 \pm 0.06 \\
-4.88 \neq 0.13\end{array}$ & $\begin{array}{l}1.4 \\
-4.43 \\
-3.0\end{array}$ \\
\hline
\end{tabular}

- Uncertainties are given as standard deviations based on three to six runs. Values taken from ref 6 . c Values for log $K$ and $\Delta H$ (de. termined calorimetrically) taken from ref 4 . The $T \Delta S$ values were calculated by us from these data.

Crystallographic structures of neither III and IV nor their cation complexes are yet available, therefore the donor atoms involved in cation binding are unknown. However, the effects of the carbonyl groups (in III and IV) and the additional $-\mathrm{CH}_{2}$ group (in IV) are to alter the cation complexation such that the $\log K$ values for the reactions of all three cations with III or IV compared to those with I are markedly lowered, and to significantly modify the selectivity pattern found for the reaction of $I$ with these cations. The data in Table $I$ show a considerably larger decrease in $\log _{\mathrm{A}}$ for formation of the $\mathrm{Ba}^{2+}$ than the $\mathrm{Na}^{+}$or $\mathrm{K}^{+}$complex in going from 1 to IV than from I to III resulting in a $\mathrm{K}^{+}, \mathrm{Ba}^{2+}$ stability sequence for IV which is opposite to that found for I and III.

The $\log K$ values in Table $I$ show the cation selectivity pattern for IV to be similar to that for II in that $\mathrm{K}^{+}>\mathrm{Ba}^{2+}$. The significance of this finding is that it demonstrates the possibility of designing synthetic macrocyclic molecules containing oxygen donor atoms which will have cation selective properties similar to those of valinomycin and other naturally occurring cyclic antibiotics. Such synthetic molecules can then be used as models for the investigation of biological cation transport and selectivity processes.

The $\log K$ and $\Delta H$ values were determined by a calorimetric titration procedure which has been described. 8

Compound III was prepared by slowly dripping diglycolyl dichloride $(16.0 \mathrm{~g}, 0.094 \mathrm{~mol})$ and tetraethylene giycol ( 18.2 g. $0.094 \mathrm{~mol}$ ) in separate addition funnels to $1 \mathrm{~L}$ of rapidly stirring benzene at $50^{\circ} \mathrm{C}$. After stirring 48 h at $50^{\circ} \mathrm{C}$, the benzene was removed under reduced pressure and the product was distilled: $9.6 \mathrm{~g}$ (35\%), bp $148^{\circ} \mathrm{C}(0.16 \mathrm{Torr})$, mp 78.5-79.5 ' $C$. In a second run using larger proportions, the product was extracted from the crude reaction mixture using hot hexane. After recrystallization from hexane, the yield and physical properties of the product isolated by this method were comparable to those of the distilled product. Compound III exhibited the following spectra: $I R, 1735 \mathrm{~cm}^{-1}(C=0)$; $N M R$ 8, $3.63\left(\mathrm{~s}, 8 \mathrm{H}, \mathrm{OCH}_{2} \mathrm{CH}_{2} \mathrm{O}\right), 3.71\left(\mathrm{~m}, 4 \mathrm{H}, \mathrm{COOCH}_{2} \mathrm{CH}_{2} \mathrm{O}\right)$, $4.28\left(\mathrm{~s}, 4 \mathrm{H}, \mathrm{COCH}_{2} \mathrm{O}\right), 4.35\left(\mathrm{~m}, 4 \mathrm{H}, \mathrm{COOCH}_{2}\right)$.

Anal. Calcd for $\mathrm{C}_{12} \mathrm{H}_{20} \mathrm{O}_{8}$ : $\mathrm{C}, 49.31 ; \mathrm{H}, 6.90 ; \mathrm{mol} \mathrm{wt}, 292.3$. Found: C, 49.27; H, 6.87; mol wt, 297.

The preparation and characterization of compound IV were previousiy reported 9 but we now present an improved method for its isolation. This compound was prepared by slowly dripping malonyl dichioride ( $45.5 \mathrm{~g} .0 .323 \mathrm{~mol}$ ) and pentaethyiene glycol $(87.0 \mathrm{~g}, 0.323 \mathrm{~mol})$ in separate addition funnels to $1 \mathrm{~L}$ of rapidly stirring benzene at $50^{\circ} \mathrm{C}$ under a nitrogen atmo- 
2366

sphere. After stirring $72 \mathrm{~h}$, the benzene was removed under reduced pressure and the product was extracted from the cruide using hot hexane. This method gave $12.32 \mathrm{~g}$ (10.8\%) of prodvet: $\mathrm{mp} 65.3-66.0^{\circ} \mathrm{C}: \mathrm{IR}, 1740 \mathrm{~cm}^{-1}(\mathrm{C}=0)$; NMR $\delta 3.48$ (s, $\left.2 \mathrm{H}, \mathrm{COOCH} \mathrm{CH}_{2} \mathrm{COO}\right), 3.70\left(\mathrm{~s}, 12 \mathrm{H}, \mathrm{COCH}_{2} \mathrm{CH}_{2} \mathrm{O}\right), 3.79$ (t. $\left.4 \mathrm{H}, \mathrm{COOCH}_{2} \mathrm{CH}_{2} \mathrm{O}\right), 4.36\left(t, 4 \mathrm{H}, \mathrm{COOCH}_{2}\right.$ ).

Anal. Calod for $\mathrm{C}_{13} \mathrm{H}_{2}, \mathrm{O}_{3}$ : C. 50.98; H, 7.24; mol wt, 306.3. Fouad: C, 50.90; H, 7.40; mel wt, 306.

Acknowledgments. Financial support of this study from the National Science Foundation (Grant CHE76-10991) and US. Public Health Service (GM $18811-04)$ is acknowledged.

References and Notes

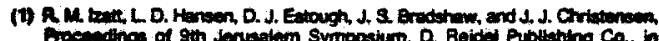

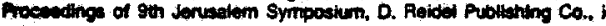

Fin.

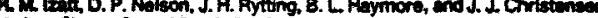
LAn Cham. SoC., 93, 1619 (1971).

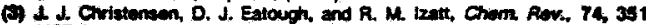

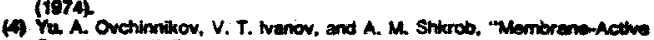
Comploxones", Elsevier, New York. N.Y., 1974.

E Grell, $T h$. Funck, and F. Eggers in "Momoranes", Q. Elsemmen, Et, Vol. n, Mreal Dekker, New York. N.Y., 1974.

A. M lzath, J. D. Lamb, B. L Haymore, G. C. Woech and S. J. Christenean. th properation.

M K. Dalley in "Synthotic Mutidentato Macrocyclic Compounds". R. M. brill

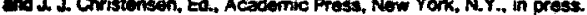
R. M. kath, R.E. Terry, 8. L. Haymore. L. D. Hansen, N. K. Dalloy. A. G Av ondet, and J. J. Christensan, J. Am. Chem. Soc. 92, 7620 (1976).

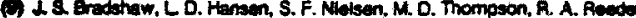

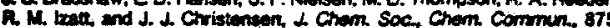
(tors)

R. M. Izatt, J. D. Lamb, G. E. Mazs, R. E. Asay

4. S. Bradshaw, J. J. Christensen

Department of Chemistry and Contribution No. 105 Thermochemical Institute, Brigham Young University

Prowe, Uiah 84602

Reariand Decumber 28, 1976

From J. Am. Chem. Soc., 99. 
Submitted to I. Am. Chem. Soc.

April 12, 1977

UNUSUAL STABILITY CHARACTERSTICS OF A NEW PYRIDINE SUBSTITUTED

CYCLICPOLYETHER-ESTER COMPOUND WITH $\mathrm{Na}^{+}, \mathrm{K}^{+}, \mathrm{Ag}^{+}$, and $\mathrm{Ba}^{2+}$

IN METHANOL--COMPARISON WITH OXYGEN, SULFUR AND NITROGEN ANALOGS

Sir:

Since the discovery of the cation-binding properties of macrocyclic antibiotics, cyclic polyethers and cryptands, a host of synthetic macrocycles involving a wide variety of structures has been reported in attempts to duplicate, if not improve, on the cation selectivity of these 1 igands. 1,2 Unfortunately, in only a few cases have the thermodynamic and kinetic cation binding properties of newly developed macrocyclic ligands received systematic investigation, leaving unanswered many questions which might give direction to further synthetic work. In addition to cation recognition and separation, these ligands also exhibit potential application in the field of catalysis. Use of carefully designed synthetic crown ethers as catalysts has been investigated by Cram and coworkers, who have already succeeded in catalyzing transacylation reactions resembling those catalyzed by the enzyme trypsin. ${ }^{3}$ In a recent communication, van Bergen and Kellogg 4 report the synthesis of an unusual macrocycle $\frac{1}{2}$ which incorporates into the ring Hantzsch esters, which because of their hydride donating properties may be used in place of NAD(P)H. Their goal was to enhance hydrịde transfer by adding a crown ether ring onto the ester in hopes of holding metal cations, which are known to catalyze this transfer, in close proximity to the hydride donor.

We report here the synthesis of new pyridine $2_{2}^{2}$ and sulfur $\mathfrak{Z}^{3}$ substituted cyclic polyether-ester compounds and the characterization of their cation 
binding properties with $\mathrm{Na}^{+}, \mathrm{K}^{+}, \mathrm{Ba}^{2+}, \mathrm{Ag}^{+}$, and $\mathrm{Cu}^{2+}$. The pyridinecontaining ligand is similar in structure to that reported by van Bergen and $\mathrm{Kellogg}^{4}$ and has been found to possess rather unusual complexation characteristics differing significantly from its analogs which do not contain the pyridine moiety.

We have already noted ${ }^{5}$ that a considerable drop both in cation complex stability and in cation selectivity is seen upon addition of two carbonyl

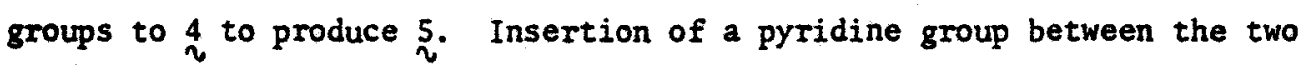
ester carbonyl oxygens to yield 2 results in an unexpected rise in $\log \mathrm{K}$ (Table I) for complex formation over that found for the parent ligand, $\mathbf{j}$, for all metal ions studied except $\mathrm{Cu}^{2+}$ where there is no evidence of reaction with any of the ligands investigated. This stability enhancement in the case of the alkali metal cations and $\mathrm{Ag}^{+}$is in sharp contrast to the reported ${ }^{6}$ reduction in complex stability of 6 where nitrogen has been substituted for oxygen in the 18-crown-6 ring.

The possibility exists that it is not the presence of the nitrogen donor which is responsible for the unexpectedly high stability of complexes of $\underset{q}{2}$, but rather the presence of the aromatic ring, which might alter the effect of the carbonyl groups on the complexation. This hypothesis is under current investigation, both by synthetic and complexation studies and by $X$-ray structure determinations. If indeed the effect is conformational in origin, this factor will be important to the understanding of Hantzsch ester crown complexation with metal ions.

We have obtained additional structural information concerning 2 and $\underset{n}{5}$ and their $\mathrm{K}^{+}$complexes from infra-red spectra using $\mathrm{KBr}$ wafers. The 
spectrum of $\underset{2}{5}$ shows the two carbonyl groups to be in different environments, the carbonyl stretching frequencies being 1715 and $1730 \mathrm{~cm}^{-1}$. However, upon complexation with $\mathrm{K}^{+}$, we observe a single carbonyl stretch at $1740 \mathrm{~cm}^{-1}$. From this finding we conclude that (i) since the carbonyl stretch has been shifted to a higher frequency, the complex probably does not involve the carbonyl oxygen atoms, and (ii) the molecule is highly organized around the central $\mathrm{K}^{+}$. We have completed $\mathrm{X}$-ray structure determinations of 5 and its $\mathrm{K}^{+}$complex ${ }^{7}$ and find the results to be consistent with the infra-red spectral findings. The spectra of 2 and its $\mathrm{K}^{+}$complex do not show this marked change in the infra-red spectra probably because the pyridine moiety imparts organization and rigidity to the ring both in the uncomplexed and complexed forms.

The thermodynamic data in Table I show that the increased stability of complexes of $2_{2}^{2}$ over that of complexes of the parent macrocycle $2_{2}$ is due almost entirely to the enthalpy term in the case of the monovalent cations. However, a significant drop in entropy stabilization for the $\mathrm{Ba}^{2+}$ complex of 2 from that of $2_{2}^{5}$ results in the reversal of the $\mathrm{K}^{+}-\mathrm{Ba}^{2+}$ selectivity sequence between these two ligands. It is rather uncommon for macrocycles to bind $\mathrm{K}^{+}$more strongly than $\mathrm{Ba}^{2+}$ as in the case of 2 inasmuch as these cations have nearly identical crystal radii. In fact, this selectivity sequence is one of the distinguishing features of valinomycin and certain other naturally occurring antibiotic macrocycles. 5 A few crown ethers and cryptands containing bulky hydrophobic groups duplicate this selectivity, as does another series of carbonylcontaining crowns recently synthesized by us. 8 
A compound similar to 2 , but without carbonyl groups has been synthesized by Newcomb, et al. ${ }^{9}$ They report that this 1 igand has much greater affinity for t-butyl ammonium ion than does 18-crown-6.

The replacement of an oxygen atom in 5 by sulfur produces 3 which shows no heat of reaction with $\mathrm{Na}^{+}, \mathrm{K}^{+}$, or $\mathrm{Ba}^{2+}$. The large size of the sulfur may force the sulfur atom out of the ring, as in the case of sulfur-substituted 18 -crown-6. ${ }^{10}$ The observation that $3_{2}$ complexes alkali metal ions even more poorly than 1,10-dithia-18-crown-6, 7, suggests that the steric consideration mentioned, namely orjentation of the sulfur atom away from the ring, if present in 3 does not enhance carbonyl. participation in complexation. If this conclusion is extended to the case of the pyridine-containing ligand, it would support the idea that the pyridine nitrogen, not the ester carbonyls, is responsible for its unusual behavior.

The $\log K, \Delta H$, and $T \Delta S$ values were obtained by a calorimetric titration procedure which has been described previously. ${ }^{11}$ Ligand 2 was standardized by calorinetric titration with $\mathrm{K}^{+}$and found to be $98.2 \%$ pure. It was not possible to standardize 3 by this direct procedure since the $\log \mathrm{X}$ value for formation of the $\mathrm{Ag}^{+}$complex was not suf-. ficiently high to produce an end point. Variation of a ligand purity factor in the curve fitting computer routines used for data analysis indicated that 3 is greater than $98 \%$ pure.

To prepare 2, 2,6-pyridinedicarboxylic acid chloride $20.4 \mathrm{~g}$ (0.1 mole) and $19.4 \mathrm{~g}(0.1$ mole) tetraethylene glycol, both in $200 \mathrm{ml}$ of a 50:50 mixture of tetrahydrofuran and benzene, were slowly added while stirring to 1 liter of benzene at $50^{\circ} \mathrm{C}$. The resulting reaction mixture was stirred for 48 hours. After cooling, the mixture was filtered and 
the solvents were removed under vacuum. The resulting light viscous oil was repeatedly extracted with hot hexane to yield. $25.4 \mathrm{~g}$ (77\%) of a white solid; $\operatorname{mp} 83.5-85^{\circ}$; ir, $1720 \mathrm{~cm}^{-1}(\mathrm{C}=0) ; \operatorname{nmr}(\delta), 3.85(\mathrm{~s}, 8 \mathrm{H}$, $\left.\mathrm{CH}_{-2} \mathrm{OCH}_{-2}\right), 3.95\left(\mathrm{t}, 4 \mathrm{H}, \mathrm{COOCH}_{2} \mathrm{CH}_{2} \mathrm{O}\right), 4.63\left(\mathrm{t}, 4 \mathrm{H}, \mathrm{COOCH}_{2}\right)$ and 8.0-8.5 (m, $3 \mathrm{H}$, aromatic $\mathrm{H})$.

Anal. Caled for $\mathrm{C}_{15} \mathrm{H}_{19} \mathrm{NO}_{7}$ : C, $55.38 ; \mathrm{H}, 5.88 ; \mathrm{H}, 4.31 ; \mathrm{MW}, 325.32$. Found: $\mathrm{C}, 55.46 ; \mathrm{H}, 5.96 ; \mathrm{N}, 4.47 ; \mathrm{MW}, 329$.

Compound $\underset{2}{3}$ was prepared by slowly dripping $19.0 \mathrm{~g}$ (0.102 mole) thiodiglycolyl dichloride and $19.7 \mathrm{~g}$ (0.102 mole) tetraethylene glycol, each diluted to $150 \mathrm{ml}$ with benzene, from separate addition funnels into 1 liter of rapidly stirring benzene at $50^{\circ} \mathrm{C}$. After stirring 68 hrs at $50^{\circ} \mathrm{C}$, the benzene was removed under reduced pressure and the product was distilled: $6.29 \mathrm{~g}(20 \%)$, b.p. $181^{\circ} \mathrm{C} / 0.4 \mathrm{~mm}$ m.p. $41-43^{\circ} \mathrm{C}$. The product was recrystallized from chloroform:ether yielding long white needles m.p. $43.5-44.5^{\circ} \mathrm{C}$. Compound 3 exhibited the following spectra: ir 1740 . $\mathrm{cm}^{-1}(\mathrm{C}=0) ; \mathrm{nmr}(\delta) 3.54\left(\mathrm{~s}, 4 \mathrm{H}, \mathrm{COCH}_{2} \mathrm{~S}\right), 3.71\left(\mathrm{~s}, 8 \mathrm{H}, \mathrm{OCH}_{2} \mathrm{CH}_{2} \mathrm{O}\right), 3.77$ (m, $\left.4 \mathrm{H}, \mathrm{COOCH}_{2} \mathrm{CH}_{2} \mathrm{O}\right), 4.36$ (II, $4 \mathrm{H}, \mathrm{COOCH}_{2}$ ).

Anal. Caled for $\mathrm{C}_{12} \mathrm{H}_{20} \mathrm{O}_{7} \mathrm{~S}: \mathrm{C}, 46.74 ; \mathrm{H}, 6.54 ; \mathrm{S}, 10.40$; mol. wt. 308.35. Found: C, 46.95; H, 6.62; S, 10.48; mol. wt. 306 .

\section{ACKNOWLEDGMENTS}

Financial support of this study from the National Science Foundation (Grant CHE 76-10991) and the U.S. Public Health Service (GM18811-04) is acknowledged. 


\section{REFERENCES}

1. J. J. Christensen, D. J. Eatough, and R. M. Izatt, Chem. Rev., 74, 351 (1974).

2. Y. A. Ovchinnikov, V. T. Ivanov, and A. M. Shkrob, "Membrane-Active Complexones," Elsevier, New York, 1974.

3. Y. Chao and D. J. Cram, J. Am. Chem. Soc., 98, 1015 (1976).

4. T. J. van Bergen and R. M. Kellogg, J.C.S. Chem. Commun., 964 (1976).

5. R. M. Izatt, J. D. Lamb, G. E. Maas, R. E. Asay, J. S. Bradshaw, and J. J. Christensen, J. Am. Chem. Soc., 99, 2365 (1977).

6. H. K. Frensdorff, J. Am. Chem. Soc., 93, 600 (1971).

7. N. K. Dalley, S. B. Larson, G. E. Maas, R. E. Asay, R. M. Izatt, and J. J. Christensen, in preparation.

8. R. M. Izatt, J. D. Lamb, J. S. Bradshaw, S. F. Nielsen, G. E. Maas, M. D. Thompson, and J. J. Christensen, in preparation.

9. M. Newcomb, G. W. Gokel, and D. J. Cram, J. Am. Chem. Soc., 96, 6810 (1974).

10. N. K. Dalley, J. S. Smith, S. B. Larson, K. L. Matheson, J. J. Christensen, and R. M. Izatt, J.C.S. Chem. Commun., 84 (1975).

11. R. M. Izatt, R. E. Terry, B. L. Haymore, L. D. Hansen, N. K. Dalley, A. G. Avondet, and J. J. Christensen, J. Im. Chem. Soc., 98, 7620 (1976). R. M. Izatt ${ }^{\star}$, J. D. Lamb, R. E. Asay, G. E. Maas, J. S. Bradshaw, and J. J. Christensen Departments of Chemistry and Chemical Engineering and Contribution No. 114, Thermochemical Institute Provo, Utah 84602 
Table I

$\log \mathrm{K}, \Delta H(\mathrm{kcal} / \mathrm{mol})$, and $\mathrm{T} \Delta \mathrm{S}(\mathrm{kcal} / \mathrm{mol})$ Values for the Interaction of Several Macrocycle Ligands with Metal Ions in $\mathrm{CH}_{3} \mathrm{OH}$ at $25^{\circ} \mathrm{C}$ and $\mu=0.1$

\begin{tabular}{|c|c|c|c|c|c|c|}
\hline Ligand & & $\mathrm{Na}^{+}$ & $\mathrm{x}^{+}$ & $\mathrm{Ba}^{2+}$ & $\mathrm{Ag}^{+}$ & $\mathrm{Cu}^{2+}$ \\
\hline \multirow[t]{3}{*}{2} & $\log K$ & $4.29+0.06$ & $4.66 \pm 0.02$ & $4.34 \pm 0.02$ & $4.88 \pm 0.05$ & \\
\hline & $\Delta H$ & $-6.19 \pm 0.08$ & $-9.3 \pm 0.2$ & $-6.03 \pm 0.03$ & $-7.83 \pm 0.03$ & $\mathbf{a}$ \\
\hline & $T \Delta S$ & -0.34 & -2.9 & -0.11 & -1.17 & \\
\hline \multirow[t]{3}{*}{$3^{3}$} & $\log K$ & & & & $3.05 \pm 0.05$ & \\
\hline & $\Delta \mathbf{H}$ & $a$ & $\mathbf{a}$ & a & $-6.97 \pm 0.08$ & $\mathbf{a}$ \\
\hline & $\mathrm{T} \Delta \mathrm{S}$ & & & & -2.81 & \\
\hline \multirow[t]{3}{*}{$\stackrel{4}{2}$} & $\log x$ & $4.36^{b}$ & $6.05^{b}$ & $7.0^{\mathrm{b}}$ & $4.58+0.03$ & \\
\hline & $\Delta H$ & $-8.4^{b}$ & $-13.4^{b}$ & $-10.2^{b}$ & $-9.15 \pm 0.11$ & a. \\
\hline & TAS & $-2.4^{b}$ & $-5.5^{b}$ & $-0.2^{b}$ & -2.90 & \\
\hline \multirow[t]{3}{*}{$\mathbf{5}$} & $\log K$ & $2.5^{b}$ & $2.79^{b}$ & $3.1^{b}$ & $2.50 \pm 0.07$ & \\
\hline & $\Delta \mathbf{H}$ & $-2.3^{b}$ & $-5.9^{b}$ & $-0.5^{b}$ & $-1.53 \pm 0.12$ & $\mathbf{a}$ \\
\hline & $\mathrm{T} \Delta \mathrm{S}$ & $1.1^{b}$ & $-2.1^{b}$ & $3.8^{b}$ & 1.88 & \\
\hline 2 & $\log x$ & & $3.90^{c}$ & & $3.3^{\mathrm{c}}$ & \\
\hline 7 & $\log K$ & & $1.15^{c}$ & $\cdots$ & & \\
\hline $\mathbf{R}$ & $\begin{array}{l}\text { ng of } \\
K \text { is } s \\
\text { rence }\end{array}$ & $\begin{array}{l}\text { e heat other } \\
\text { ese cations } \\
11 \text { and/or th }\end{array}$ & $\begin{array}{l}\text { than heat of } \\
\text { and Iigands. } \\
\text { e enthalpy ch }\end{array}$ & $\begin{array}{l}\text { f dilution wa } \\
\text { This result } \\
\text { hange is near }\end{array}$ & $\begin{array}{l}\text { found for th } \\
\text { indicates tha } \\
\text { zero. } b_{\text {Refer }}\end{array}$ & ce 5 . \\
\hline
\end{tabular}



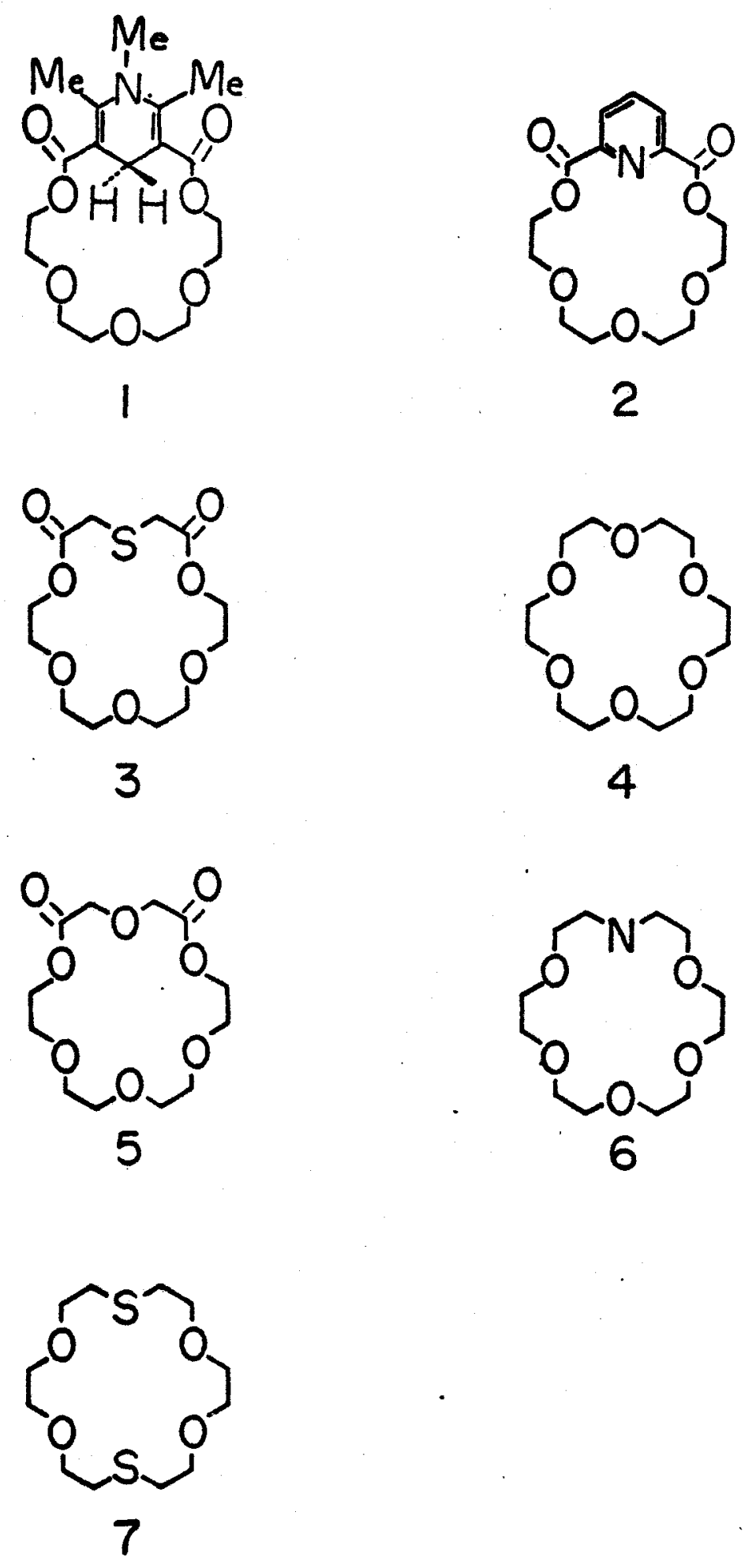
THE SYNTHESIS OF NOVEL MACROCYCLIC MULTIDENTATE

COMPOUNDS FROM DIOXODIOIC ACIDS

\author{
R. Elliott Asay \\ Department of Chemistry \\ M. S. Degree, August 1977
}

\begin{abstract}
A series of novel macrocyclic multidentate crown compounds have been prepared from a series of dioxodioic acids. The dioxodioic acids were prepared by treating various oligoethylene glycols or amines with maleic, succinic, citraconic, and glutaric anhydrides. The crown compounds were then synthesized from the dioxodioic acid chlorides obtained from the diacids and various oligoethylene glycols or ethylene diamine.

COMIITTEE APPROVAL:
\end{abstract}

